Universidade de São Paulo

Faculdade de Odontologia de Ribeirão Preto

Departamento de Materiais Dentários e Prótese

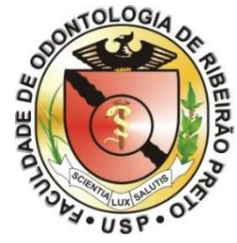

FLÁVIA CRISTINA TARGA COIMBRA

\title{
AÇÃO ANTIMICROBIANA DE PERÓXIDOS ALCALINOS FRENTE A MICRORGANISMOS ESPECÍFICOS
}




\title{
AÇÃO ANTIMICROBIANA DE PERÓXIDOS ALCALINOS FRENTE A MICRORGANISMOS ESPECÍFICOS
}

\author{
Dissertação apresentada à Faculdade de Odontologia de \\ Ribeirão Preto, Universidade de São Paulo, para obtenção do \\ título de Mestre, junto ao Departamento de Materiais \\ Dentários e Prótese. \\ Área de Concentração: Reabilitação Oral
}

Orientadora: Profa. Dra. Helena de Freitas Oliveira Paranhos

\section{VERSÃO CORRIGIDA}

\section{Ribeirão Preto}


AUTORIZO REPRODUÇÃO E DIVULGAÇÃO TOTAL OU PARCIAL DESTE TRABALHO, POR QUALQUER MEIO CONVENCIONAL OU ELETRÔNICO, PARA FINS DE ESTUDO E PESQUISA, DESDE QUE CITADA A FONTE.

\section{FICHA CATALOGRÁFICA}

Elaborada pela Biblioteca Central do Campus USP - Ribeirão Preto

Coimbra, Flávia Cristina Targa

Ação Antimicrobiana de Peróxidos Alcalinos frente a microrganismos específicos. Ribeirão Preto, 2014.

82p. : il. ; $30 \mathrm{~cm}$

Versão corrigida da Dissertação. A versão original se encontra disponível na Biblioteca da Unidade sede do Programa.

Dissertação de Mestrado, apresentada à Faculdade de Odontologia de Ribeirão Preto/USP. Área de concentração: Reabilitação Oral .

Orientadora: Paranhos, Helena de Freitas Oliveira

1. Biofilmes. 2. Higienizadores de dentadura.

3. Peróxidos Alcalinos. 4. Ação Antimicrobiana.

5. Prótese total. 
FOLHA DE APROVAÇÃO

\section{FLÁVIA CRISTINA TARGA COIMBRA}

Ação antimicrobiana de peróxidos alcalinos frente a microrganismos específicos.

Dissertação apresentada à Faculdade de Odontologia de Ribeirão Preto da Universidade de São Paulo para a obtenção do título de Mestre.

Área de Concentração: Reabilitação Oral

Data da defesa: ___ _ _ _ 2014

Banca Examinadora

Prof.(a) Dr.(a)

Instituição:

Julgamento:

Assinatura:

Prof.(a) Dr.(a)

Instituição:

Julgamento:

Assinatura:

Prof.(a) Dr.(a)

Instituição:

Julgamento:

Assinatura: 
Dedicatória 
A Deus, pela força e proteção.

Aos meus pais, Dulcinete e Antônio Carlos pelo amor, dedicação, carinho e apoio incondicional que tornarem possível a realização dos meus sonhos.

A minha querida irmã, Thais, pelo amor, dedicação, apoio, amizade, e preocupação para que nada me faltasse. Pelo cuidado e carinho de sempre que nos tornaram grandes companheira.

Aos meus avôs $\mathcal{N}$ elson e Florinda, pelo amor incondicional e eterno, pelo carinho, pelos exemplos de vida, por tudo que me proporcionaram e pela dedicação que me fez chegar até aqui.

$\mathcal{A}$ todos que torceram por mim e me incentivaram, meu muito obrigada! 
Agradecimento $E_{\text {special }}$ 
À Profa $\operatorname{Dr}^{a} \mathcal{H}$ elena de Freitas Oliveira Paranhos, minha orientadora, pelo exemplo, ensinamentos, dedicação, oportunidade, confiança, e por tornar possivvel a realização desse trabalho. Ter trabalhado ao seu lado e sob sua orientação durante estes anos foi um motivo de grande orgulho e honra para mim. 
Agradecimentos

e 
À Faculdade de Odontologia de Ribeirão Preto da Universidade de São Paulo, representada pelo Diretor Prof. Dr. Valdemar Mallet da Rocha Barros, pela oportunidade de cursar o Mestrado.

\section{À Profa Dra Fernanda de Carvalho Panzeri Pires de Souza,} Coordenadora do Programa de Pós-Graduação na área de Reabilitação Oral, pela dedicação, incentivo, orientação e exemplo.

À CAPES (Coordenação de Aperfeiçoamento de Pessoal de Nivivel Superior), pela bolsa de mestrado concedida.

À Profa $\operatorname{Dr}^{a}$ Cláudia Helena Lovato da Silva, pela amizade, dedicação, carinho, atenção, ensinamentos e pelo exemplo de ser humano e profissional.

Ao Prof. Dr. Raphael Freitas de Souza, pela atenção, dedicação, amizade, incentivos, confiança, disponibilidade em todos os momentos em que precisei de sua ajuda. Meu eterno agradecimento.

Ao Prof. Dr. Evandro Watanabe, por todo o apoio prestado.

Aos Professores do Departamento de Materiais Dentários e Prótese, da Faculdade de Odontologia de Ribeirão Preto da Universidade de São Paulo, por todos os ensinamentos e contribuição essencial para minha formação.

A Ana Paula Macedo, pela fundamental ajuda na estatística, pela paciência, pelos conselhos, dedicação, amizade, disponibilidade e ajuda para tornar possivvel a realização deste trabalho. Meu eterno agradecimento. 
Às Funcionárias da Secretaria do Programa de Pós-Graduação em Reabilitação Oral da Faculdade de Odontologia de Ribeirão Preto da Universidade de São Paulo, Regiane de C. Tirado Damasceno, Ana Paula Xavier e Fermanda Talita de Freitas, pela dedicaçõ, atenção e disponibilidade.

Aos Funcionários da Seção de Pós-Graduação da Faculdade de Odontologia de Ribeirão Preto da universidade de São Paulo, Isabel Cristina Galino Sola, Regiane Cristina Moi Sacilloto, Leandro Marin Silva, Mary Possani Carmessano, pela paciência, disponibilidade, ajuda e orientações.

À Técnica do laboratório de Reabilitação Oral, da Faculdade de Odontologia de Ribeirão Preto da Universidade de São Paulo, Viviane de Cássia Oliveira, pela dedicação, convivência, carinho, suporte técnico e auxílio para a realização desse trabalho.. Muito obrigada por sua ajuda, pelos seus ensinamentos, sugestões e conselhos.

A Ana Paula Macedo, pela fundamental ajuda durante as leituras de cor e rugosidade, e por seus conhecimentos repassados.

Aos

Aos técnicos, Edson Volta e Ricardo S. Antunes, pela essencial colaboração na etapa de confecção dos corpos de prova.

A todos os colegas da Pós-Graduação, pela amizade, carinho, atenção, apoio e por todos os momentos de convivência. Obrigada pelas ideias $e$ conhecimentos compartilhados, que foram essenciais para minha formação pessoal e profissiona. 
Aos meus amigos e companheiros de laboratório, Marcela Salles Moreira, Danilo B. Sorgini, Carolina N. F. Arruda, Daniela G. Ribeiro, Vanessa M. F. Leite, Juliana B. Pinheiro Tatiana R. Cunha, Maria Paula Della Vecchia, Adriana B. Ribeiro, Maurício M. Badaró, e Marina P. Vomero. Obrigado a todos pela convivência, carinho, conselhos, ensinamentos, por todas as vezes que precisei de ajuda. Obrigada por fazerem parte da minha história e me ajudarem na realização desse trabalho.

Meu eterno agradecimento a todos que participaram direta ou indiretamente para a realização desse trabalho. 
Resumo

e exe 
COIMBRA, F.C.T. Ação antimicrobiana de peróxidos alcalinos frente a microrganismso específicos. Ribeirão Preto, 2014. 82p. Dissertação (Mestrado em Reabilitação Oral). Faculdade de Odontologia de Ribeirão Preto, Universidade de São Paulo.

\section{RESUMO}

Uma característica importante de um higienizador de prótese total refere-se à sua ação antimicrobiana. Este estudo avaliou, por meio de estudo in vitro, o efeito de higienizadores de próteses totais a base de peróxido alcalino frente a biofilmes microbianos formados em superfícies de resina acrílica. A partir de matrizes circulares metálicas $(15 \mathrm{~mm} \times 3 \mathrm{~mm})$, foram confeccionados corpos de prova de resina acrílica termopolimerizável (Lucitone 550), os quais foram esterilizados em micro-ondas (650W, por 6 minutos) e inoculados com suspensão de $10^{7} \mathrm{UFC} / \mathrm{mL}$ dos microrganismos: Candida albicans (Ca), Candida glabrata $(\mathrm{Cg})$, Staphylococcus aureus (Sa), Streptococcus mutans (Sm), Bacillus subtilis (Bs), Enterococcus faecalis (Ef), Escherichia coli (Ec) e Pseudomonas aeruginosa (Pa). Após contaminação, os corpos de prova foram incubados a $37^{\circ} \mathrm{C}$ por $48 \mathrm{hs}$ e, em seguida, por meio de uma cesta de aço inoxidável, foram imersos em Béquer com as seguintes soluções, de acordo com as instruções do fabricante $(n=10)$ : Grupo CP (Controle positivo)- Solução PBS; Grupo MI - NitrAdine, Medical Interporous; Grupo EF - Efferdent Plus; Grupo CT - Corega Tabs e Grupo CN - (Controle negativo $n=5$ ) - sem contaminação e imersão em PBS. Em seguida, foram lavados (PBS) e imersos em meio de cultura Letheen, para a avaliação da esterelidade e obtenção das diluições seriadas, as quais foram semeadas em meios de cultura específicos. Após incubação ( $37^{\circ} \mathrm{C}$ por $24 \mathrm{hs}$ ), de acordo com morfologia típica, o número de colônias características foi mensurado e o número de $\mathrm{UFC} / \mathrm{mL}$ calculado. Os dados foram transformados em log10 (UFC+1) e analisados estatisticamente (KruskalWallis e Dunn) $(\alpha=0,05)$. Os resultados mostraram diferença significativa entre os grupos para os microrganismos avaliados ( $\mathrm{Ca} p<0,001 ; \mathrm{Cg} p<0,001 ; \mathrm{Sm}$ $p<0,001$; Sa $p<0,001$; Bs $p=0,005$; Ef $p<0,001$; Ec $p<0,001$ e $P a p<0,001$ ), havendo redução significativa de UFC de Ca [MI: $0,81(0,17$ a 2,51)], $\mathrm{Cg}$ [MI: $0,00(0,01$ a 2,40)], Sa [Ml: $0,00(-0,15$ a 1,43)], Sm [Ml: 0,00 (-0,09 a 1,21); EF: 2,00 (0,77 a $2,49)$, Bs [CT $0,00(-0,19$ a 1,64)], Ef [MI: $0,00(-0,18$ a 0,88$)]$, Ec [MI: $0,00 \quad(-0,44$ a 1,15); EF: 0,00 (-0,09 a 1,15); CT: $0,00(-0,21$ a 0,99$)]$ e de Pa [MI: $0,00(-0,20$ a $0,53)$ ] quando comparados aos grupos controles positivos. Concluiu-se que o higienizador NitrAdine foi o mais efetivo, causando diminuição o número de UFC em 7 dos 8 microrganismos testados.

Palavras-chave: prótese total, biofilmes, higienizadores de dentadura, peróxidos alcalinos, ação antimicrobiana, 
Abstract (20) 
COIMBRA, F.C.T. Complete Denture Cleansers: antimicrobial action of alkaline peroxide against specific microorganisms. Ribeirão Preto, 2014. 82p. Dissertation (Master's Degree in Oral Rehabilitation). Ribeirão Preto School of Dentistry, University of São Paulo, Brazil.

\begin{abstract}
The antimicrobial action is an important characteristic of a denture cleanser. This study evaluated, through in vitro study, the efficacy of alkaline peroxides about the antimicrobial action against microbial biofilms on acrylic resin surfaces. Denture base acrylic resin specimens (Lucitone 550; $n=190$ ) were obtained from circular metal matrix $(15 \mathrm{~mm} \times 3 \mathrm{~mm}$ ) and sterilized with microwave (650W, for 6 minutes), contaminated with suspension $10^{7} \mathrm{UFC} / \mathrm{mL}$ of Candida albicans (Ca), Candida glabrata $(\mathrm{Cg})$, Staphylococcus aureus (Sa), Streptococcus mutans (Sm), Bacillus subtilis (Bs), Enterococcus faecalis (Ef), Escherichia coli (Ec) and Pseudomonas aeruginosa $(\mathrm{Pa})$. After contamination, the specimens were incubated at $37^{\circ} \mathrm{C}$ for 48 hours and then through a stainless steel basket, were immersed in becker with the following solutions according to the manufacturer's instructions $(n=10)$ : Group CP (Positive Control) - PBS solution; Group MI - NitrAdine, Medical Interporous; Group EF - Efferdent Plus; Group CT - Corega Tabs e Group CN - (Negative Control - $n=5$ ) - no contamination and immersed in PBS. After incubation (37- $\mathrm{C}$ por $24 \mathrm{hs}$ ), in accordance with characteristic morphology, the number of characteristic colonies was counted and the number of $\mathrm{CFU} / \mathrm{mL}$ calculated. Data were processed following transformation into the formula $\log 10(\mathrm{CFU}+1)$ and statistically analyzed (KruskalWallis and Dunn) $(\alpha=0.005)$. The results showed significant differences between groups for evaluated microorganisms (Ca $\mathrm{p}<0,001 ; C g \mathrm{p}<0,001 ; \mathrm{Sm} \mathrm{p}<0,001$; $\mathrm{Sa}$ $p<0,001$; $B s p=0,005$; Ef $p<0,001$; Ec $p<0,001$ e $P a p<0,001)$, with a significant reduction in the number of CFU the $\mathrm{Ca}[\mathrm{Ml}: 0,81(0,17 \mathrm{a} 2,51)], \mathrm{Cg}$ [MI: $0,00(0,01 \mathrm{a}$ 2,40)], Sa [Ml: $0,00(-0,15$ a 1,43)], Sm [Ml: 0,00 (-0,09 a 1,21); EF: 2,00 (0,77 a $2,49)$ ], Bs [CT $0,00(-0,19$ a 1,64)], Ef [MI: $0,00(-0,18$ a 0,88$)]$, Ec [MI: $0,00 \quad(-0,44$ a 1,15); EF: 0,00 (-0,09 a 1,15); CT: $0,00(-0,21$ a 0,99)] and Pa [Ml: 0,00 (-0,20 a $0,53)$ ] when compared with CP Groups. It was concluded that the cleanser NitrAdine was the most effective, causing a decrease the number of CFU in 7 of 8 microorganisms tested.
\end{abstract}

Keywords: complete denture, biofilms, denture cleansers, peroxide alkaline,. 
Sumário

(20) 


\section{SUMÁRIO}

1 INTRODUÇÃO

2 REVISÃo dE LITERATURA

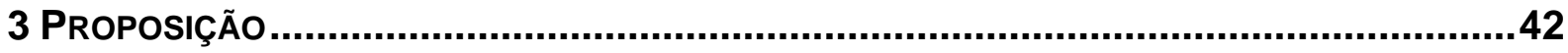

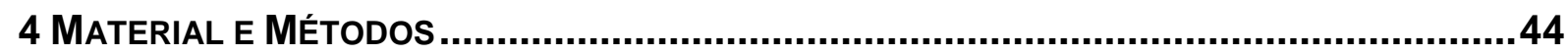

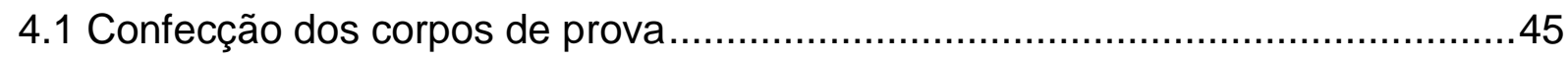

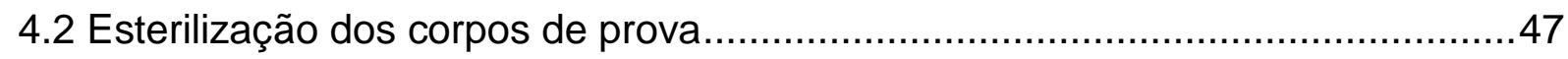

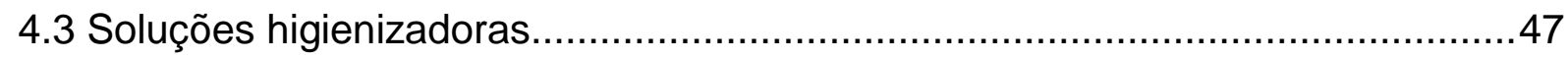

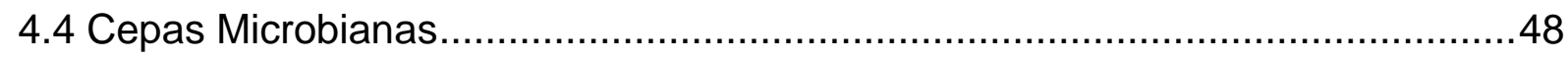

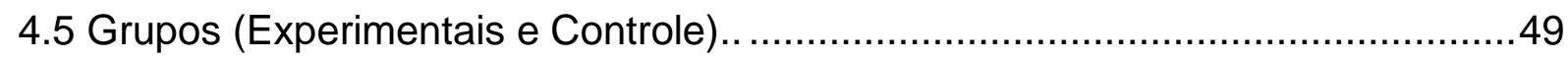

4.6 Meios de cultura empregados para preparação do inoculo microbiano, contaminação e avaliação da esterilidade/contaminação .........................................50

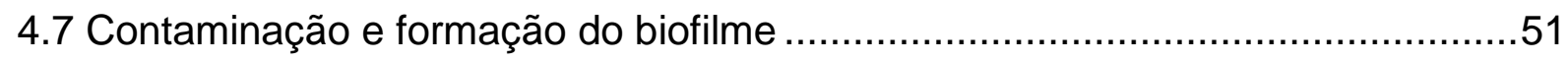

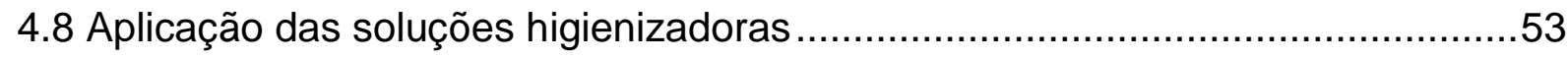

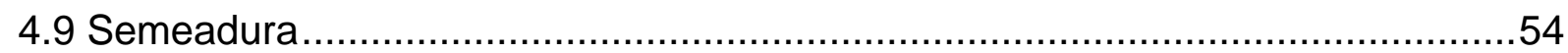

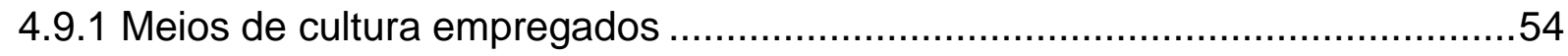

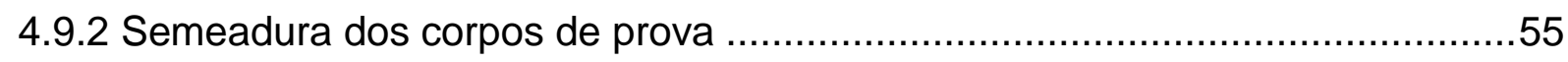

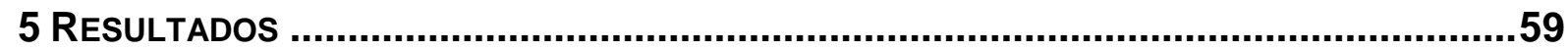

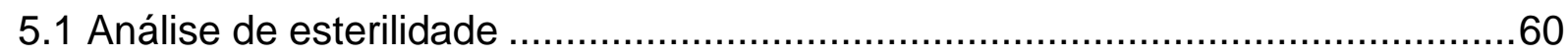

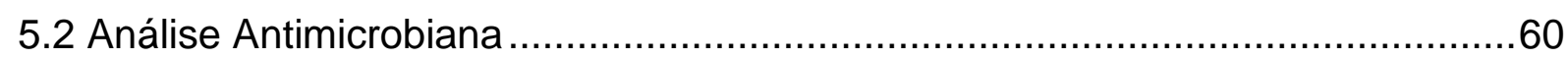

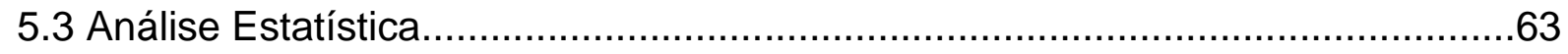

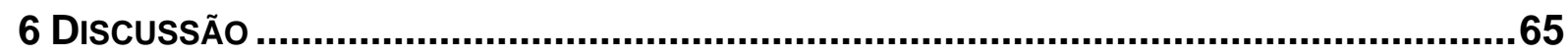

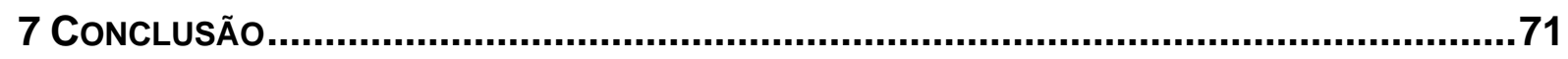

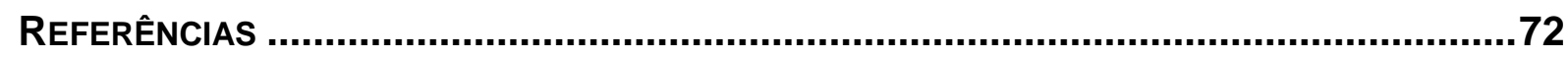


Introdução

(2) 


\section{INTRODUÇÃO}

A prótese total tem a função de restabelecer a função e estética, contribuindo para o bem-estar físico e psicológico do paciente desdentado total e consiste em tratamento reabilitador amplamente utilizado (Zarb et al., 2013). Porém, para que ela cumpra seu papel reabilitador, são necessários cuidados de manutenção do aparelho protético, sendo a higienização um importante item a ser considerando (Telles, 2009; Azevedo; Cerca, 2012).

Estudos mostram que a saúde oral de usuários de próteses totais é precária (Marchini et al., 2004, 2006; Dikbas et al., 2006; Catão et al., 2007; Akar et al., 2008; Haumschild et al., 2009; Pace et al., 2010; Peracini et al., 2010). A má higiene está associada à falta de orientação adequada, às características anatômicas das próteses, à diminuição da destreza manual e acuidade visual dos pacientes e à ineficácia dos higienizadores de próteses (Council on dental materials, instruments and equipment, 1983; Silva-Lovato et al., 2006; Akar et al., 2008). Outro fator também a ser destacado refere-se às características intrínsecas da resina acrílica, principal material constituinte das próteses totais, que apresenta superfície rugosa e propensa à retenção de biofilme (Glass et al., 2010)

Sendo assim, as próteses totais podem tornar-se colonizadas por uma camada densa de comunidade complexa de microrganismos conhecida como "Biofilme" (Nikawa et al., 1998). O biofilme da prótese total atua como reservatório de microrganismos oportunistas, os quais podem causar não somente infecções locais, como a Candídiase Atrófica Crônica (Estomatite Protética) (Arendorf; Walker, 1987; Barbeau et al., 2003; Coelho; Souza; Daré, 2004; Kossion et al., 2011), mas também sistêmicas, como respiratórias, gastrointestinais e cardíacas (Sumi et al., 2002; Coulthwaite et al., 2007; Coco et al., 2008; Glass et al., 2010; Pereira-Cenci et al., 2010). Além disso, o contato das próteses dentárias com os tecidos orais, saliva e sangue cria um meio para a transferência de microrganismos responsáveis pela contaminação cruzada (De Paola et al., 1984; Rudd et al. 1984; Henderson et al, 1987; Powell et al., 1990). Estudos identificaram espécies de Streptococcus, Staphylococcus, Escherichia coli, Acinetobacter, Pseudomonas aeruginosa, Enterobacter, Klebsiella pneumoniae, bem como espécies de Candida em cultivos oriundos de próteses contaminadas e pedra pomes de laboratórios dentais (Depaola et al., 1983, Powell et al, 1990). Esses microrganismos, em sua maioria, também 
estão relacionados a doenças locais e sistêmicas, como infecções do trato urinário, pneumonia, conjuntivite e meningite (Senpuku et al., 2003; Coulthwaite, Verran, 2007; Glass et al., 2010; El-Sohl 2011). Sendo assim, visando o controle do biofilme, uma das características fundamentais de um higienizador de prótese total refere-se à sua ação antimicrobiana.

Vários agentes são indicados para a remoção do biofilme, sendo classificados, de uma forma geral, em mecânicos (escovação e ultrassom), físicos (energia de micro-ondas), químicos (hipocloritos alcalinos, peróxidos, ácidos, drogas brutas, detergentes e enxaguatórios bucais) e associados (mecânico/físico e químico) (Budtz-Jørgensen, 1979; Abelson, 1981, 1985; Jagger; Harrison, 1995; Nikawa et al., 1999; Shay, 2000; Neppelembroek et al., 2003; Silva-Lovato et al., 2006). Os métodos químicos são classificados, de acordo com sua composição e mecanismo de ação, em hipocloritos alcalinos, peróxidos alcalinos, peróxidos neutros com enzimas, ácidos, drogas brutas, detergentes e enxaguatórios bucais (Nikawa et al., 1999). Tais produtos, quando utilizados como higienizadores de prótese, à exceção dos ácidos, são empregados por meio da imersão, geralmente por 8 horas, denominada imersão longa (noturna), ou por 20 minutos, denominada imersão curta (Nikawa et al., 1999; Shay, 2000; Felton et al., 2011).

Entre os agentes químicos de imersão, as soluções de peróxidos alcalinos são amplamente indicadas e empregadas por usuários de próteses totais (Nikawa et al, 1999; Shay et al., 2000; Felton et al., 2011), sendo compostos por agentes oxidantes, efervescentes, redutores da tensão superficial e quelantes, sendo apresentados na forma de pós ou tabletes, os quais, em contacto com a água, tornam-se soluções de peróxido de hidrogênio. Apresentam simplicidade de uso e odor agradável, constituindo-se em método popular de higiene (Cumming et al., 1990; Jagger; Harrison, 1995; Shay, 2000; Roessler, 2003), sendo comum sua indicação em associação ao método mecânico de escovação (Paranhos et al., 2007a,b; Souza et al., 2009; Felton et al., 2011).

Em relação à efetividade antimicrobiana dos peróxidos, os resultados são contraditórios. Alguns estudos mostraram ineficácia antimicrobiana desses produtos (Budtz-Jørgensen et al., 1978; Ghalichebaf et al., 1982; Ferreira et al., 2009; Lee et al., 2009; Montagner et al., 2009; Souza et al., 2009); porém, outros experimentos têm demonstrado que os peróxidos incorporam uma ação desinfetante ao processo de higienização, podendo ser úteis frente ao controle do biofilme de próteses 
totais(Nakamoto et al., 1991; Gornistsky et al., 2002; Pavarina et al., 2003; SilvaLovato et al., 2010; Sirnivisan et al., 2010; Dhamande et al., 2012; Ramage et al., 2012; Lucena-Ferreira et al., 2014).

Um fator importante a ser destacado refere-se ao microrganismo avaliado. Experimentos avaliaram a ação antimicrobiana de peróxidos frente às cepas de $S$. mutans, bem como aeróbios (Fernandes et al., 2010; Li et al., 2010; De Andrade et al, 2011; Lucena-Ferreira et al., 2014); porém, a maioria dos estudos está direcionada às cepas de C. albicans. (Nakamoto et al., 1991; Coenye et al., 2008; Ferreira et al., 2009; José et al., 2010; Li et al., 2010; Uludamar et al., 2010; Vieira et al., 2010; Andrade et al., 2011; Iseri et al., 2011; Lee et al., 2011; Kumar et al., 2012).

A efetividade de um método de higienização deve ser avaliada não somente por meio de testes clínicos, mas também laboratoriais, uma vez que os estudos laboratoriais possibilitam o conhecimento do comprotamento dos microrganismos individualmente frente aos produtos avaliados (Nikawa et al.,1999). Deste modo, uma avaliação de peróxidos, considerando parâmetros microbiológicos, faz-se importante, sendo essencial que essa análise seja realizada frente a microrganismos patógenos comumente presentes na microbiota bucal (André et al., 2011) e considerados indicadores na avaliação da efetividade de um método de desinfecção ou esterilização (Cole, Robinson, 1996). Sendo assim, este trabalho investigou o efeito de higienizadores de próteses totais à base de peróxidos alcalinos frente a biofilmes microbianos formados em superfícies de resina acrílica. 
Revisão de Literatura 


\section{REVISÃo de LiterAturA}

Estudos laboratoriais (in vitro) têm sido conduzidos com o objetivo de avaliar a ação antimicrobiana de higienizadores químicos de próteses totais à base de peróxidos alcalinos e mostram resultados variados.

Moore, Smith e Kenny (1984) compararam a eficácia de oito produtos de limpeza de próteses totais quanto à eliminação de microrganismos aeróbicos, anaeróbicos e leveduras. Na primeira parte do estudo foi avaliada a eficácia dos seguintes higienizadores de prótese, frente à cultura de C.albicans: Denalan, Efferdent, Polident; Mersene, Clorox-Calgon e Miller's. Diluições seriadas, obtidas a partir de culturas de C. albicans foram tratadas com os higienizadores, sendo que os produtos foram testados nas concentrações de um quarto, meio e na concentração recomenda pelo fabricante. Amostras foram coletadas após 15, 30 e 60 minutos de exposição aos higienizadores. Diluições seriadas obtidas a partir dessas amostras foram semeadas em Agar dextrose Sabouroud e incubadas por 72 horas em temperatura ambiente. Após contagem do número de Unidades Formadoras de Colônia (UFC), os resultados mostraram que os higienizadores Mersene, CloroxCalgon e o Miller's tiveram a mesma ação antifúngica nas diferentes concentrações e tempos avaliados. O Efferdent, o Polident e o Denalan foram os menos eficazes. $\mathrm{Na}$ segunda parte do estudo foi avaliada a eficácia dos higienizadores (Mersene, Polident, Kleenite, Clorox-Calgon e escovação com sabão Ivory) na remoção de microrganismos presentes nas próteses de 12 pacientes. Os pacientes foram instruídos a usar as próteses como de rotina e armazená-las em água quando não estivessem sendo usadas e a não utilizar nenhum higienizador abrasivo ou químico. As próteses foram distribuídas nos grupos: Grupo 1) Higienizadores de imersão ( 30 minutos), Grupo 2) Escovação com Água e Sabão (60 segundos) e Grupo 3) Imersão em Água destilada (Controle - 30 minutos). Após os procedimentos de higienização, cada prótese foi imersa em solução salina, por 10 segundo, para remoção de resíduos químicos e em seguida foram obtidas diluições de cada amostra, as quais foram semeadas e incubadas. Os resultados mostraram que o Miller's e o Kleenite foram os mais eficazes. O Clorox-Calgon foi efetivo na remoção das leveduras em condições laboratoriais, mas não foi efetivo nas condições clínicas. Os autores concluíram que os higienizadores de prótese devem ser efetivos 
na sanitização dos aparelhos protéticos e não somente eficazes na remoção de manchas e depósitos.

Nakamoto et al. (1991) avaliaram a afetividade de higienizadores de próteses a base de peróxidos alcalinos (com e sem enzimas) frente a Candida albicans (cepas padrão). As soluções higienizadoras foram avaliadas quanto à capacidade fungicida e de remoção da $C$. albicans aderida à resina acrílica. Foram utilizados 01 higienizador sem enzimas (Polident), 01 com enzimas líticas das leveduras e enzimas proteolíticas (Pika) e 03 com enzimas proteolíticas (Liodent, Dr. Health e Polident). Soluções fúngicas foram preparadas, diluídas (3 $\times 10^{7}$ celulas $/ \mathrm{mL}$ ) e empregadas para realização de testes líticos de leveduras, do efeito fungicida e de habilidade de remoção de cepas de Candida aderidas à resina acrílica. Os resultados mostraram que todos os higienizadores apresentaram ação lítica; porém, após 120 minutos, o higienizador Polident (com enzimas) apresentou a melhor ação. Quanto ao teste fungicida, todos os higienizadores eliminaram as cepas de $C$. albicans em período de tempo de 5 a 30 minutos, exceto o higienizador Pika. Quanto à habilidade de remoção de Candida, embora os cinco higienizadores tenham apresentado ação, os melhores resultados foram registrados para os higienizadores com enzimas, com melhores resultados para o higienizador Dr. Health. Os autores concluíram que a afetividade foi mais dependente do peróxido alcalino do que das enzimas.

Drake et al. (1992) avaliaram a eficácia de higienizadores de imersão de prótese contra $C$. albicans e $S$. mutans. Corpos de prova retangulares $(15 \times 25 \mathrm{~mm})$ foram obtidos a partir da bases de próteses. As espécies de Candida albicans e Streptococcus mutans foram semeadas em Sabouraud a $37^{\circ} \mathrm{C}$, em condições aeróbicas durante 24 horas e em TSB-YE $\left(5 \%\right.$ de $\left.\mathrm{CO}_{2}\right)$ a $37^{\circ} \mathrm{C}$ durante 24 horas, respectivamente. Em seguida, os corpos de prova foram contaminados e higienizados: 1) Pastilha efervescente à base de peróxido alcalino (Efferdent-12 minutos), 2) Pastilha efervescente à base de peróxido alcalino (Polident-12 minutos). Em seguida foram lavadas em água destilada estéril. Amostras das superfícies de cada corpo de prova foram coletadas, colocadas em PBS estéril e sonificadas por 10 segundos, para obtenção das diluições. Em seguida, as diluições foram semeadas em Agar TS2OB (5\% de $\mathrm{CO}_{2}$ ) por 48 horas e em Agar Saboraud, em condições aeróbicas, por 24 horas. Os resultados mostraram que tanto o Efferdent, como o 
Polident, foram efetivos na redução da aderência de S.mutans e ambos os higienizadores foram ineficazes contra C.albicans.

Nikawa et al. (1995a) avaliaram a atividade antifúngica de 11 higienizadores de próteses totais sobre o biofilme de Candida albicans, assim como avaliaram a compatibilidade desses higienizadores com condicionadores teciduais. Foram empregados 11 higienizadores (Denture Cleanser Tablets, Efterdent, 2-layered Efterdent, Kleenite, Pika, Double Action Polident, Polident for Partials, Super Strength Polident, Polident Powder, Smoker's Polident e Stain Away) e 6 condicionadores teciduais (Coe Comfort, Coe Soft, Fit Softer, GC Soft Liner, Hydrocast e Visoogel). Os resultados mostraram que todos os higienizadores reduziram a viabilidade fúngica, com melhores resultados para o Super Strength Polident. Todos os higienizadores também reduziram a atividade antifúngica, com melhores resultados para kleenite, Polident for Partials, Efferdent, Denture Cleanser Tablet e Super Strength Polident. Os autores concluíram que as alterações nos condicionadores teciduais variaram de acordo com o período de imersão, higienizador e condicionador empregados.

Nikawa et al. (1995b) avaliaram a eficácia de higienizadores de próteses na redução da atividade de C.albicans no biofilme. Onze higienizadores foram distribuídos em 5 grupos: 1) peróxidos alcalinos (Steradent), 2) peróxidos neutros com enzimas (Doctor Health, Dent Free, Nisodent, Polident e Liodent), 3) enzimas (Clean Soft, Pika e Plakick), 4) Drogas Cruas (Spa dent) e 5) Desinfetante (emuCAE). Todos os produtos foram usados segundo as recomendações dos fabricantes. Espécimes de resina acrílica $(50 \times 50 \times 0,7 \mathrm{~mm})$ (Bio Resin, Shofu) foram confeccionados de acordo com as instruções do fabricante, contaminados com suspensão de $C$. albicans e incubados a $37^{\circ} \mathrm{C}$ por 2 horas. Em seguida, $2 \mathrm{~mL}$ do meio de cultura Sabouraud foi colocado em cada poço com o corpo de prova contaminado e incubados por 144 horas a $37^{\circ} \mathrm{C}$. Após esse período, os espécimes foram imersos nas soluções higienizadoras por 2 horas, lavados com água destilada e em seguida, incubados em $2 \mathrm{~mL}$ de meio Sabouraud broth modificado. $\mathrm{O} \mathrm{pH}$ de cada amostra foi determinado por um peagâmetro após 25 e 30 horas de incubação para avaliar a atividade residual do biofilme. Foram avaliados o efeito fungicida, a capacidade lítica de Candida e a habilidade de redução da atividade fúngica do biofilme. Além disso, os espécimes foram avaliados por meio de microscopia eletrônica de varredura (JMS-6300). Os resultados mostraram que os peróxidos, os 
peróxidos neutros e os higienizadores Clean Soft, Pika e EmuCAE eliminaram completamente a levedura em 2 horas de incubação. Todos os higienizadores, exceto o Pika, não apresentaram ação lítica Candida significativa. O higienizador Dent Free apresentou a maior capacidade de redução da atividade fúngica do biofilme. A análise em microscopia mostrou que os peróxidos, os peróxidos neutros e o higienizador EmuCAE apresentaram a maior habilidade de remoção do biofilme de Candida e o higienizador Spa Dent (droga crua), a menor.

Coenye et al. (2008) investigaram a efetividade de um sistema in vitro de formação de biofilmes (Dispositivo de Robbins modificado - MRD) em materiais frequentemente utilizados na fabricação de aparelhos orais, como dentaduras, aparelhos ortodônticos, protetores bucais ou aparelhos auditivos. Além disso, avaliaram a eficácia de um novo higienizador à base de peróxido alcalino (Medical Interporous) na remoção de biofilmes microbianos. O sistema foi empregado para a avaliação da formação de biofilmes de Candida albicans, Streptococcus mutans, Staphylococcus aureus resistentes à meticilina (MRSA) e $P$. aeruginosa sobre amostras circulares (2mm de altura, 6,8 $\mathrm{mm}$ de diâmetro e área superficial de 36 $\mathrm{mm}^{2}$ ) confeccionadas de substratos de poli metil-metacrilato (PMMA), silicone de uso médico, hidroxiapatita e elastômero. Após a formação de biofilme, as amostras foram tratadas com 04 higienizadores à base de peróxido alcalino: 1) NitrAdine $^{\mathrm{TM}}$ (Medical Interporous - 15 minutos); 2) Polident (GlaxoSmithKline); 3) Steradent (Reckitt \& Benckiser); e 4) Efferdent Plus (Pfizer). Todos os produtos foram utilizados de acordo com o as instruções do fabricante. O grupo controle foi tratado com água. Após o tratamento, as amostras foram transferidas para tubos com solução de $\mathrm{NaCl}$ e submetidos a 3 ciclos de 30 segundos com ultra-som e à agitação em vórtex por 30 segundos para remoção das células fracamente aderidas. Após obtenção das diluições, estas foram semeadas em Sabouraud Dextrose Aga(SDA) para C. albicans, Brain Heart Infusion (BHI) para S. mutans e Tryptic soy Agar (TSA) para $S$. aureus e $P$. aeruginosa. As placas foram incubadas a $37^{\circ} \mathrm{C}$ por 24 horas, o número de colônias foi contado e as Unidades Formadoras de Colônias calculadas. Todos os experimentos foram conduzidos em pelo menos 03 amostras. Além disso, o biofilme de $C$. albicans foi avaliado por meio de microscopia de fluorescência (Olympus $\mathrm{GmbH}$ ) e de varredura (Nikon) e o número de células planctônicas após o uso do NitrAdineTM foi mensurado. Os resultados mostraram que o sistema foi eficaz, resultando na formação de uma massa densa e madura de biofilme, 
independentemente do microrganismo ou do substrato empregados. $O$ higienizador NitrAdine TM foi eficaz na remoção de todos os biofilmes, apresentando efetividade contra C. albicans em todos os substrato avaliados. O Polident, Efferdent,e Steradent apresentaram menor efetividade, principalmente para biofilmes de $C$. albicans formado em PMMA. Os autores verificaram também que a diminuição da temperatura e o aumento do volume de água e do tempo de exposição reduzem a eficácia dos higienizadores, ressaltando a necessidade do seguimento das instruções dos fabricantes.

Silva et al. (2008) avaliaram a eficácia de higienizadores de próteses (hipoclorito de sódio a $1 \%$, digluconato de clorexidina a $2 \%$, glutaraldeído a $2 \%$, vinagre a $100 \%$, pastilhas efervescentes à base de perborato de sódio e perborato de sódio a 3,8\%) na desinfecção de espécimes de resina acrílica (Jet) contaminados por Candida albicans, Streptococcus mutans, S. aureus, E. colie e B. subtilis, por meio da contagem das Unidades Formadoras de Colônias (UFC). O grupo controle era constituído de espécimes contaminados que não haviam sido submetidos à desinfecção. Cada um dos 350 espécimes foi transferido para um tubo de ensaio contendo meio de cultura (Tripticsoy ou Sabouroud) inoculado com a suspensão de cada microrganismo. Após incubação, os espécimes foram imersos nas soluções higienizadoras por 10 minutos e posteriormente em solução salina para desprendimento das células fracamente aderidas. Diluições decimais seriadas $\left(10^{0}\right.$ a $\left.10^{-3}\right)$ foram realizadas a partir dessas soluções resultantes e, em seguida, semeadas em placas de petri contendo meios de cultura específicos (Tripticsoy ou Sabouraud). Após o período de incubação, o número de Unidades Formadoras de Colônias foi contado. Os resultados mostraram que o hipoclorito de sódio a 1\%, a clorexidina a $2 \%$ e o glutaraldeído a $2 \%$ foram os métodos mais eficazes contra todos os microrganismos testados, seguidos pelo vinagre a $100 \%$, o perborato de sódio a $3,8 \%$ e as pastilhas efervescentes à base de perborato de sódio.O perborato de sódio a $3,8 \%$ foi mais efetivo que as pastilhas efervescentes à base de peróxido tanto contra C.albicans como para S.mutans. A rugosidade superficial aumentou após desinfecção com perborato de sódio a 3,8\%. Os autores concluíram que o hipoclorito de sódio a 1\%, o glutaraldeído a $2 \%$, a clorexidina a $2 \%$ e o perborato de sódio a 3,8\% consistem em alternativas válidas para a desinfecção da resina acrílica.

Ferreira et al. (2009) verificaram a eficácia de higienizadores frente à aderência da Candida albicans e Candida glabrata sobre reembasadores de próteses. Verificaram também a correlação entre rugosidade de superfície e níveis 
de aderência microbiana. Foram selecionados três materiais: reembasadores à base de polimetil metacrilato macio (CoeSoft) e duro (Kooliner); e reembasador à base de silicone macio (Ufi gepl P). As amostras foram preparadas de acordo com as orientações dos fabricantes e tiveram suas rugosidades superficiais medidas (Perfilômetro Surfcorder SE 1700). Para simular as condições clínicas, cada amostra recebeu uma película de revestimento salivar obtida de um voluntário saudável. Em seguida, as amostras foram colocadas em tubos contendo $10 \mathrm{~mL}$ de Sabouraud broth (Difco) e suspensões de C. albicans e C. glabrata. Após a inoculação, os tudos contendo as amostras foram incubados por $2 \mathrm{~h}$ a $37^{\circ} \mathrm{C}$ e, em seguida, lavados com PBS (15 segundos) e distribuídas aleatoriamente em quatro grupos: T1: água destilada por 15 minutos (controle negativo), T2: solução higienizadora enzimática (Polident 3 minutes) por 3 minutos, T3: solução higienizadora (Efferdent) por 15 minutos; ou T4: solução de hipoclorito de sódio a $0,5 \%$ por 10 minutos (T4). Os tabletes efervescente foram imersos em $30 \mathrm{~mL}$ de água destilada deionizada a $40^{\circ} \mathrm{C}$. Após os procedimentos, as amostras foram lavada em PBS, fixadas com cristal violeta durante 1 minuto, enxaguadas com PBS e as células fúngicas aderidas foram contadas por meio de um microscópio óptico (Axiostar 2 Plus) (x400), sendo os resultados expressos em células $/ \mathrm{mm}^{2}$. Os resultados mostraram que não houve diferença estatística significante da rugosidade da superfície entre CoeSoft e o Kooliner. O Ufi gepl P apresentou a superfície mais lisa. Células de $C$. albicans e $C$. glabrata foram encontradas sobre os materiais após os tratamentos. O CoeSoft apresentou o maior número de células aderidas quando comparado com o Kooliner. A colonização geral em todos os materiais diminuiu significativamente com o tratamento com $\mathrm{NaOCl}$,, $5 \%$. Todos os outros tratamentos apresentaram a mesma quantidade de células quando comparados com o grupo controle para ambas as espécies de Candida. O número de células de $C$. glabrata foi maior para todos os tratamentos, exceto para o $\mathrm{NaOCl}$ a $0,5 \%$, em comparação com $C$. albicans. Não houve correlação entre a rugosidade da superfície e adesão de $C$. glabrata e $C$. albicans em todos os substratos.

Gedik et al. (2009) avaliaram a eficácia de higienizadores de próteses na desinfecção de forradores resilientes, bem como a rugosidade de superfície e a capacidade de adesão de Candida albicans desses materiais. Cinquenta e seis espécimes foram preparados para cada um dos materiais testados: Mollosil, SoftLiner; Moloplast B e Luci Soft. Após a medição da rugosidade de superfície inicial 
dos espécimes, estes foram contaminados com suspensão de C.albicans e incubados a $37^{\circ} \mathrm{C}$ por 90 minutos. Em seguida, foram lavados com PBS e imersos, por 120 minutos, em $40 \mathrm{~mL}$ de solução de cada um dos sete higienizadores de próteses: Peróxidos Alcalinos (Efferdent, Polident, Steradent e Corega), Ácido clorídrico a 6,5\% (Denclen), Gluconato de Clorexidina 0,12\% (Klorhex) e Hipoclorito Alcalino 5,25\% (Axion). Em seguida, cada espécime foi lavado em PBS, fixado com formaldeído e o número de células de $C$. albicans que aderiram à superfície de cada espécime foi contada por meio de um microscópio, sendo expresso pela proporção de células remanescentes após a exposição a cada higienizador em comparação ao grupo controle (água destilada esterilizada). Os resultados mostraram que não houve relação entre o tipo de polimerização do material e a capacidade de adesão de $C$. albicans, pois não houve diferença significativa entre os valores de rugosidade médias das superfícies dos materiais. Todos os higienizadores foram eficazes na remoção de Candida, apesar de não prevenirem a adesão de Candida. Embora nenhuma diferença tenha sido observada entre os higienizadores, os autores consideraram que o hipoclorito alcalino Axion foi o desinfetante mais eficaz; e que os produtos Corega, Polident, Denclen, Steradent e Efferdent obtiveram os melhores resultados em relação à limpeza dos espécimes.

Lee et al. (2009) avaliaram a eficácia de higienizadores frente à erradicação de biofilmes planctônicos, recentemente aderidos, estabelecidos e maduros de Staphylococcus aureus resistentes à meticilina (MRSA-15 e MRSA-16) em corpos de prova de resina acrílica. Foram empregados 03 higienizadores: Solução de hipoclorito de sódio a $2 \%$ (Soçução de Milton); Solução desinfetante $2 \%$ isenta de aldeído e com liberação de oxigênio (Perform) e Solução $1.5 \%$ de solução de peróxido alcalino (Steradent). Inicialmente, foi determinada a Concentração Inibitória Mínima dos agentes antimicrobianos. O biofilme artificial foi formado sobre espécimes de resina acrílica (Rapid Repair) com o auxílio de um dispositivo de formação de biofilmes (Constant Deplh Film Fermenter-CDFF). Foram analisados os biofilmes de 04 fases: planctônico, séssil (4 horas), estabelecido (24 horas) e maduro (120 horas). Os espécimes foram retirados após 4, 24 e 120 horas de formação de biofilme e imersos (imersões curtas) em cada agente antimicrobiano ou em solução salina (controle) por 1, 5 ou 10 minutos. Em seguida colocados em solução tampão e agitado por um minuto para obtenção das diluições seriadas, as quais foram semeadas em BD Columbia Agar e incubadas por 24 horas. Após esse 
período, as colônias foram contadas e a porcentagem de células viáveis calculada. As amostras também foram preparadas para análise em microscopia eletrônica de varredura (Zeiss). Os resultados da $\mathrm{CIM}$ mostraram que $\circ \mathrm{NaOCl}$ foi o mais efetivo com CIM de $0.03 \%$, Perform com $0.12 \%$ e Steradent com $0.38 \%$ (MRSA-16) e $0.09 \%$ (MRSA-15). Os higienizadores foram efetivos contra MRSA em biofilme de 4 horas, com o hipoclorito a $2 \%$ sendo efetivo com exposição de 1 minuto. Os biofilmes de 24 e 120 horas foram mais resistentes à ação dos higienizadores, com o Steradent e Perform sendo menos eficazes; porém, o hipoclorito a $2 \%$ apresentou efetividade com apenas 1 minuto de imersão para todos os biofilmes formados. $O$ Steradent foi o higienizador menos eficaz. Os autores concluíram que os biofilmes de MRSA (120h) são difíceis de erradicar, e que o único higienizador capaz de erradicar todos os biofilmes de MRSA-15 e 16 foi o hipoclorito a $2 \%$. Os autores salientaram que a falta ou inadequada higienização podem ser prejudiciais à saúde do paciente, pois podem ser fonte de reinfecção, principalmente em pacientes idosos e hospitalizados.

Montagner et al. (2009) estudaram a ação antifúngica de diferentes agentes de limpeza sobre espécimes de resina acrílica (Vipi Wave) polimerizadas por microondas, sem polimento e previamente inoculados com Candida albicans. Sessenta espécimes $(10 \times 10 \times 5 \mathrm{~mm})$ foram inoculados com a cepa de $C$. albicans e incubados por 3 horas a $37^{\circ} \mathrm{C}$. Os espécimes foram distribuídos em 05 grupos experimentais e dois grupos controles: G1: clorexidina a 2,0\% (10 minutos); G2: hipoclorito de sódio a 0,5\% (10 minutos); G3: hipoclorito de sódio modificado (hipoclorito de sódio 0,5\% e álcool 96GL - 10 minutos); G4: peróxido alcalino Corega Tabs (5 minutos); G5: peróxido de hidrogênio $10 \mathrm{v}$ (30 minutos); $C 1$ : controle inoculado com $C$. albicans e imerso em solução salina (10 minutos) e C2: espécimes controle com ausência de inoculação, imerso em solução salina (10 minutos). Em seguida, cada espécime foi lavada com salina e transferida para tubos de ensaio contendo $5 \mathrm{~mL}$ de $\mathrm{BHI}$ broth e neutralizadores e incubados por 24 horas. Após esse período os tubos foram avaliados por meio de um espectrofotômetro. Alíquotas de cada tubo foram coletadas, inoculada em meio Sabourud Agar e incubadas a $37^{\circ} \mathrm{C}$ por 24 horas, para verificar o crescimento microbiano. Os resultados mostraram que somente 0 hipoclorito de sódio e o peróxido de hidrogênio a $10 \%$ apresentaram ação antifúngica contra $C$. albicans. O Corega Tabs, usado de acordo com as recomendações do fabricante, não foi eficaz na remoção da C.albicans. A solução 
de clorexidina a 2\% não inibiu o crescimento dos microrganismos mesmo após 10 minutos de imersão. Os autores concluíram que o hipoclorito de sódio e o peróxido de hidrogênio são mais eficientes frente à C.albicans do que a solução de clorexidina a $2 \%$ e agentes efervescentes.

Paranhos et al. (2009) realizaram um estudo com objetivo de comparar a eficácia de três métodos de higienização de próteses totais (químico, mecânico e associado) e os efeitos sobre diferentes microrganismos presentes em biofilmes formados em superfície de resina acrílica termicamente ativada. Foram confeccionados 220 corpos de prova ( $15 \mathrm{~mm}$ diâmetro e $4 \mathrm{~mm}$ de largura) de resina acrílica (Vipi Dental Ltda) a partir de um padrão de cera. As amostras foram esterilizadas com gás de óxido de etileno para posterior contaminação com inóculo microbiano com $10^{6} \mathrm{UFC} / \mathrm{mL}$. A contaminação foi realizada a $37^{\circ} \mathrm{C}$ durante $48 \mathrm{~h}$, para as espécies: cepas padrão (Staphylococcus aureus, Streptococcus mutans, Escherichia coli, Candida albicans, Pseudomonas aeruginosa, Enterococcus faecalis) e cepas de campo (S. mutans, C. albicans, Candida glabrata e Candida tropicalis). Após a incubação e contaminação, as amostras foram aleatoriamente distribuídas nos seguintes grupos: 1) Método químico: imersão em container com $200 \mathrm{~mL}$ de água destilada a $37^{\circ} \mathrm{C}$ e um tablete efervescente de peróxido alcalino (Bonyplus Tablets) durante 5 minutos; 2) Método mecânico: escovação com escovas dentais de cerdas macias (TEK - Johnson \& Johnson) e dentifrício para dentadura (Dentu Creme) por 20 segundos, e posterior imersão em água destilada durante 5 minutos; 3) Método associado: higienização pelo método mecânico e, em seguida, pelo método químico; 4) Controle Negativo: sem contaminação e posterior imersão em água destilada e esterilizada $(200,0 \mathrm{~mL})$ durante 5 minutos e 5) Controle positivo: contaminação e posterior imersão em água destilada e esterilizada $(200,0$ $\mathrm{mL}$ ) durante 5 minutos. Os resultaram mostraram que não houve diferença significativa entre os métodos para as cepas de $S$. mutans (padrão e experimental), $S$. aureus e $P$. aeruginosa. Já para $E$. faecalis, $C$. albicans (padrão e experimental) e C. glabrata houve efetividade dos métodos mecânico e combinado. Para E. coli e C. tropicalis, a combinação dos métodos foi mais eficaz que o método mecânico. $O$ método combinado apresentou resultados semelhantes ao método mecânico e foi mais efetivo que o químico na maioria das espécies avaliadas (Enterococcus faecalis, Escherichia coli, Candida albicans (padrão e campo), Candida glabrata e Candida tropicallis). Com base nos resultados, os autores concluíram que a eficácia 
de cada um dos métodos de higienização testados depende do tipo de biofilme microbiano formado.

Souza et al. (2009) avaliaram o efeito do bicarbonato de sódio a $5 \%$ na adesão de Candida albicans à resina acrílica termicamente ativada. Cinquenta espécimes $\left(4 \mathrm{~mm}^{2}\right)$ de resina acrílica (Artigos Odontológicos Clássico Ltda) foram obtidos utilizando uma matriz metálica. As amostras foram polidas quimicamente (Termotron PQ- 9000), esterilizados em autoclave $\left(121^{\circ} \mathrm{C} / 15 \mathrm{~min}\right) \mathrm{e}$, em seguida, foram imersos em Sabouraud e inoculados com suspensão de células de Candida albicans (ATCC 1880). Após 24 horas de inoculação a $37^{\circ} \mathrm{C}$, os espécimes foram distribuidos em quatro grupos e imersos durante 10 minutos em: bicarbonato de sódio 5\% (Labsynth), gluconato de clorexidina 0,12\% (Periogard), vinagre branco (Castelo Alimentos) e peróxido alcalino (Corega Tabs). Um grupo de controle foi incluído, no qual foi utilizado água destilada. Após os tratamentos, os espécimes foram enxaguados com água destilada esterilizada e colocados em tubos de ensaio contendo $1 \mathrm{~mL}$ de solução salina $(0,85 \%)$ e agitados durante 60 segundos para obtenções das diluições. As diluições foram semadas em Agar Sabouraud dextrose (Difco Labs), incubados a $37^{\circ} \mathrm{C}$ durante 48 horas e o número de Unidades Formadoras de Colónias (UFC) por espécime foi contado. Os resultados mostraram que apenas o gluconato de clorexidina a $0,12 \%$ e bicarbonato de sódio a $5 \%$ reduziram o número de $\mathrm{UFC} / \mathrm{mL}$, apresentando diferença significativa em comparação com o grupo controle. Os autores concluíram que o gluconato de clorexidina $0,12 \%$ foi mais eficaz na redução da adesão de Candida albicans à resina acrílica ativada termicamente, entretanto, o bicarbonato de sódio $5 \%$ também pode ser uma alternativa viável.

Fernandes et al. (2010) avaliaram a eficácia de higienizadores de próteses sobre o biofilme de Candida e biofilme multiespécies de $C$. glabrata e C. albicans em resina polimetil metacrilato polimerizada por micro-ondas e convencional. As variáveis do estudo foram o ângulo de contato, a energia livre de superfície e o número de unidades formadoras de colônia de $C$. albicans e $C$. glabrata. Corpos de prova cilíndricos (10mm de diâmetro e $2 \mathrm{~mm}$ de espessura) foram confecionados com polimetil metacrilato polimerizado por micro-ondas (Acron MC) e resina poliamida termoplástica (Fexite MP). Sequencialmente, a rugosidade superficial dos corpos de prova foi medida (rugosímetro Surfcorder SE1700), sendo padronizada, para ambas as resinas, em $0,34 \pm 0,2 \mu \mathrm{m}$. Em seguida, os corpos de prova foram 
limpos em ultra-som (Thornton T740) com água esterilizada durante 10 minutos antes da medição de energia livre de superfície. Foram empregados três líquidos para medição do ângulo de contato: água destilada, formamide e 1bromonaphthalene. $O$ ângulo de contato (9 graus) foi medido por meio da dispersão de uma gota de cada líquido $(10 \mu \mathrm{l})$ sobre a superfície de cada espécime. As imagens das gotículas foram capturadas imediatamente e os ângulos de contacto foram medidos (AutoCAD Release 14). A energia livre de superfície ( $M N \cdot m-1)$ foi calculada usando o cosseno dos valores de ângulo de contato obtidos previamente à formação de biofilmes de C. albicans (ATCC 90028), C. glabrata (ATCC 2001) e ambas as leveduras. Os corpos de prova foram cobertos por saliva e incubados por 30 minutos a $37^{\circ} \mathrm{C}$. Após a contaminação dos corpos de prova e formação de biofilme por 72 horas, estes foram tratados $(n=8)$ com: água destilada (controle negativo - 10 minutos), soluções enzimática (Polident por 3 minutos), solução higienizadora (Corega Tabs por 5 minutos), hipoclorito de sódio a 0,5\% (10 minutos - controle positivo). Após os tratamentos cada corpo de prova foi transferido para um tubo de ensaio com $3 \mathrm{~mL}$ de PBS esterilizado e sonificado (7W) por 30 segundos para obtenção de diluições seriadas que foram semeadas em CHROMAgar Candida e Agar sangue. Em seguida, foram incubadas a $37^{\circ} \mathrm{C}$ por $24-72$ horas. As Unidades Formadoras de Colônias (UFC) foram contadas utilizando esteriomicroscópio (Coleman) e os resultados expressos em UCF/mL. A energia livre de superfície da PMMA $(37,16)$ foi significativamente maior que da resina poliamida $(36,35)$. Ambos os biofilmes (simples e composto) apresentaram maior crescimento na resina poliamida. A contagem do biofilme simples de $C$. glabrata foi maior que $C$. albicans para todos os tratamentos; porém, não houve diferença entre o biofilme composto com nenhum dos dois biofilmes simples. Os higienizadores foram capazes de diminuir os níveis de Candida, porém o hipoclorito a 0,5\% foi o único agente efetivo eliminando todos os microrganismos. Os higienizadores causaram maior redução de C. albicans do que C. glabrata no biofilme composto. Os autores concluíram que ambos os higienizadores (com ou sem enzimas) foram efetivos no controle do biofilme de Candida spp, especialmente na redução de $C$. albicans, porém não foram capazes de eliminar totalmente as células de Candida dos materiais estudados, como o hipoclorito de sódio a $0,5 \%$.

Jose et al. (2010) investigaram a capacidade de quatro higienizadores de prótese em descontaminar e esterilizar superfícies cobertas por biofilme de Candida 
albicans. Dezesseis cepas de C. albicans foram isoladas de pacientes com estomatite e uma cepa padrão (ATCC 90028) foram armazenadas em ágar dextrose Sabouraud a $4^{\circ} \mathrm{C}$. Uma colônia foi inoculada em $10 \mathrm{~mL}$ de meio específico e cultivada em placas de 96 poços durante toda a noite $\left(30^{\circ} \mathrm{C}\right)$ sob agitação em estufa bacteriológica. Em seguida, foram imersas nos higienizadores de prótese: Boots Smile (peróxido alcalino - 15munitos), Medical Interporous (peróxido alcalino - 15 minutos), Steradent Active Plus (peróxido alcalino - 10 minutos) e Dentural (hipoclorito de sódio a 1,5\% - 20 minutos), seguindo as instruções do fabricante ou por 18 horas (overnight). Foram quantificadas a atividade metabólica do biofilme e a biomassa do biofilme. A MEV foi empregada para exame do biofilme. Os resultados foram obtidos pelo teste de XTT e análise de microscopia eletrônica de varredura. O higienizador Dentural foi o mais eficaz, reduzindo a biomassa em mais de $90 \%$ após 20 minutos. O Steradent Active plus foi significativamente mais eficaz em 10 minutos do que na imersão overnight. Todos os higienizadores reduziram a atividade metabólica em mais de $80 \%$ após a imersão durante a noite. O Boots Smile reduziu a atividade metabólica em apenas 15 minutos de imersão. O MEV revelou presença C. albicans após o tratamento com higienizador Dentural. O higienizador Medical Interporous TM promoveu redução de $80 \%$ a $75 \%$ após 15 minutos e 18 horas, respectivamente. Os autores concluíram que os higienizadores de prótese são efetivos contra $C$. albicans, tanto em termos de remoção, como de desinfecção; no entanto, a retenção de biofilme residual que poderia conduzir à recolonização foi observada. Os higienizadores de prótese usados foram capazes de reduzir o biofilme de $C$. albicans in vitro; no entanto, nenhum dos produtos testados foi eficaz na eliminação total de biofilmes de $C$. albicans. Segundo os autores, os métodos mecânicos alternativos são necessários para melhorar a remoção do biofilme.

$\mathrm{Li}$ et al. (2010) avaliaram a eficácia de tratamentos antimicrobianos em várias superfícies de materiais dentários. Foram confeccionadas espécimes: de hidroxiapatita (HiMed), resina acrílica (Lucitone) e porcelana (Dentsplay). Todas as amostras foram esterilizadas com etanol a $95 \%$ e ultravioleta. Foram coletadas saliva não estimulada de pessoas que não limparam os dentes por mais de $6 \mathrm{~h}$. Esta saliva foi preparada, centrifugada e semeadas. Foram avaliados biofilmes de $S$. mutans, de $C$. albicans e biofilme multiesipécies (bactérias salivares e $C$. albicans). Os espécimes foram contaminados e incubados por 20 horas em condições anaeróbicas a $37^{\circ} \mathrm{C}$, para $S$. mutans e C.albicans/saliva, e em condições aeróbicas 
para biofilmes de C.albicans (única espécie). Em seguida, foram submetidos ao tratamento com Polident (peróxido alcalino - 5 minutos) e enxaguados com PBS. Após obtenção das diluições, estas foram semeadas em meios específicos. Os controles foram tratados com PBS. O crescimento dos biofilmes foi examinado por microscópio confocal de varredura a laser (Zeiss, Jena, Alemanha) e a efetividade do tratamento com Polident pela viabilidade de Unidades Formadoras de Colônias. Os resultados mostraram que o biofilme de Candida albicans, de S. mutans, e o biofilme multiespécies cresceram nos diferentes materiais avaliados. A formação de biofilme de $C$. albicans em hidroxiapatita foi reduzida quando comparada com outros materiais, incluindo a resina acrílica. A eficácia dos tratamentos variou significativamente, dependendo do tipo de superfície. Biofilmes de uma única espécie formados em superfícies de poliestireno exibiram maior susceptibilidade ao tratamento. Os autores concluíram que o Polident foi eficaz na manutenção da higiene das próteses e que a natureza da superfície influencia algumas características do biofilme, como o acúmulo de biomassa e susceptibilidade aos tratamentos antimicrobianos.

Vieira et al. (2010) estudaram a eficácia de higienizadores de próteses em relação à recolonização do biofilme por Candida spp. formado na superfície de reembasadores. Biofilmes de C. albicans (ATCC 90028) ou C. glabrata (ATCC 2001) foram formados sobre a superfície de espécimes de reembasadores e incubados por 48 h. Em seguida, foram submetidos aleatoriamente a um dos seguintes tratamentos: peróxido alcalino com enzima (Polident 3-minutos), peróxido alcalino (Efferdent,- 15 minutos), hipoclorito de sódio a 0,5\% (10 minutos) e água destilada (15 minutos). Após os tratamentos, o biofilme dos espécimes foi desprendido por sonificação (7W - 30 segundos). As diluições obtidas a partir das soluções sonificadas foram semeadas e incubadas a $37^{\circ} \mathrm{C}$ por um período de $24-48 \mathrm{~h}$, em condições aeróbicas. As células residuais foram contadas por meio de um microscópio estereoscópico (Coleman Comp. Imp) e o resultado foi expresso em células $/ \mathrm{mL}$. Os espécimes foram enxaguados em PBS estéril e analisados por meio de microscopia eletrônica de varredura (JEOL JSM5600LV). Os resultados mostraram que o tratamento com os peróxidos alcalinos foi melhor que o controle; entretanto, não foi efetivo na remoção de Candida e na prevenção da recolonização de biofilme. O hipoclorito de sódio foi o único tratamento que removeu efetivamente o biofilme, visto que nenhuma célula viável foi encontrada após seu uso. Os autores 
concluíram que os higienizadores de próteses à base de peróxidos alcalinos não foram eficazes na remoção e prevenção da recolonização de biofilmes de Candida spp.

Iseri et al. (2011) avaliaram a eficácia de diferentes agentes de limpeza na adesão de Candida albicans à resina acrílica. Culturas de C.albicans foram inoculadas em $2 \mathrm{~mL}$ de Agar Dextrose Sabouraud (SDA) e incubadas a $37^{\circ} \mathrm{C}$ por 24 horas. Em seguida, foram centrifugadas por 10 minutos (3000 rpm), lavadas em PBS, e diluídas para obtenção de uma suspensão de $10^{6}$ células de $\mathrm{C}$. albicans $/ \mathrm{mL}$. Os 180 espécimes de resina acrílica $(10 \times 10 \times 2 \mathrm{~mm})$ foram contaminados com a suspensão, incubados a $37 \stackrel{\circ}{\mathrm{C}}$ durante 90 minutos e distribuídos nos grupos $(n=30)$ : Polident (peróxido alcalino), Efferdente (peróxido alcalino), Fittydent (peróxido alcalino), CloSYSII (Dióxido de Cloro) e Corsodyl (Gluconato de Clorexidina 0,2\% ) Os corpos de prova foram imersos em $40 \mathrm{~mL}$ de cada higienizador a $37^{\circ} \mathrm{C}$ durante 15, 30 e 60 minutos. As células fúngicas aderidas a superfícies de resina acrílica foram fixados em formaldeído e contadas por meio de um microscópico óptico. Os resultados mostraram que as soluções CloSYS e Corsodyl foram mais eficazes na remoção de $C$. albicans para todos os tempos de tratamento. Todos os peróxidos alcalinos reduziram o número de colônias de $C$. albicans, mas nenhum conseguiu eliminá-la completamente. A redução significativa do número de $C$. albicans no presente estudo sugere que o uso de enxaguatórios bucais pode ser um método adequado para a limpeza de próteses.

Lee et al. (2011) avaliaram a eficiência de seis métodos de limpeza de prótese diferentes para remoção de Candida albicans. Foram confeccionados 140 espécimes $(40 \times 12 \times 3 \mathrm{~mm})$ de resina acrílica (Lucitone 199) de acordo com as instruções do fabricante e esterilizados com óxido de etileno. Cada espécime foi colocado em tubos de ensaio com $6 \mathrm{~mL}$ de suspensão de $C$. albicans (6-7 x 107 $\mathrm{cfu} / \mathrm{mL}$ ) e incubado por $2 \mathrm{~h}$ a $37^{\circ} \mathrm{C}$. Após a contaminação os espécimes foram higienizados de acordo com os métodos ( $n=20)$ : 1) escovação com escova macia (Colgate Extra Clean) e enxague em água destilada; 2) Imersão em Polident (Peróxido alcalino - 15 minutos); 3) Associação método 2 com 1; 4) Imersão em Gluconato de Clorexidina 0,12\% (Parmason Shining - 15 minutos); 5) Irradiação de UV (ADH Health Products - 10 minutos); 6) Imersão em água destilada esterelizada (15 minutos) e 7) Controle (sem tratamento).Em seguida, foram lavados e colocados em $1 \mathrm{~mL}$ de Sabouraud dextrose broth por 10 minutos e posteriormente agitados 
durante 30 segundos. Diluições seriadas foram semeadas em Ágar Sabouraud dextrose e incubadas a $37^{\circ} \mathrm{C}$ por 24 horas e, em seguida, o número de Unidades Formadoras de Colônias (UFC) foi contado. Os resultados mostraram que o método combinado (escova de dentes e imersão Polident) foi mais eficaz na redução do crescimento de $C$. albicans. Todos os métodos foram significativamente diferentes do grupo controle. O grupo controle apresentou a maior contagem de colônias de $C$. albicans e a imersão em água destilada e esterilizada foi ineficaz na remoção de $C$. albicans. O método mecânico, o Polident e associação entre eles foram mais eficazes que o gluconato de clorexidina a $0,12 \%$ e a irradiação com luz UV. Os autores concluíram que a imersão em pastilhas efervescentes, a escovação e associação entre ambos os métodos reduziram significativamente a aderência de C.albicans à resina acrílica.

Dhamande et al. (2012), compararam a capacidade de remoção de biofilme de Candida de 3 higienizadores de próteses totais. Foram confeccionados 120 corpos de prova $(1,5 \mathrm{~mm} \times 1,5 \mathrm{~mm} \times 1,5 \mathrm{~mm})$ em resina acrílica a partir de matrizes metálicas. Em seguida, os corpos de prova foram contaminados com suspensão de $3 \times 10^{7}$ células de C.albicans $/ \mathrm{mL}$ e incubados a $37^{\circ} \mathrm{C}$, por $2 \mathrm{~h}$ em seguida, foram acrescentado $2 \mathrm{~mL}$ de Sabouround em cada poço da placa de cultura e incubados por 6 dias (144h). Os corpos de prova foram imersos nas seguintes soluções higienizadoras, por 8 horas ( $n=30 / g r u p o$ ): Viclean Power (D1- Hipoclorito de sódio), Clinsodent Power (D2- peróxido alcalino) e Fittydent Tablets (D3 - peróxido) e o número de colônias foi contado. Em uma segunda análise do estudo, a partir de préculturas de C.albicans uma suspensão de $3 \times 10^{7}$ células $/ \mathrm{mL}$ foi obtida. Para cada 5 $\mathrm{mL}$ da suspensão, foi adicionado $5 \mathrm{~mL}$ de solução higienizadora em um tubo de ensaio. Esses tubos foram incubados a $37^{\circ} \mathrm{C}$ por $5,30,60,90$ e 120 minutos. $A$ densidade óptica de cada solução (suspensão-solução higienizadora) foi avaliada por um fotocolorímetro. Como resultado, observaram uma diminuição de UFC após a imersão das amostras em todas as soluções higienizadoras. A densidade óptica diminuiu para todas as amostras, o que significou uma diminuição de células de C.albicans devido a ação dos higienizadores. Entre os higienizadores, o Viclean Powder e o Clinsodent Powerd apresentaram maior diminuição da densidade quando comparados ao Fittydent. Os autores concluíram que o higienizador Clinsodent teve maior capacidade de remoção Candida devido presença de Lauril Sulfato de Sódio. 
Kumar et al. (2012) testaram a eficácia de dois higienizadores de próteses totais disponíveis no mercado e dois produtos caseiros sobre a adesão de Candida albicans em superfície de resina acrílica Cinquenta espécimes $(10 \times 10 \times 2 \mathrm{~mm})$ de resina acrílica (DPI Heat-Cure Improved) foram confeccionados, esterilizados com luz ultravioleta por 5 minutos e distribuidos em 5 grupos: (1) Clinsodent (peróxido alcalino); (2) Fittydent (peróxido alcalino); (3) vinagre (ácido acético a 4\%); (4) vinagre diluído em água (1:2) e (5) água (controle). Após inoculação com $C$. albicans, as amostram foram incubadas por 16 horas a $37^{\circ} \mathrm{C}$ e em seguida, foram imersos nos higienizadores e avaliados por 8 horas. Após esse período, os espécimes foram lavados, fixados com metanol e corados com cristal de violeta. As células de Candida aderidas foram contadas por meio de microscópio óptico. Todos os higienizadores testados reduziram o número de células de $C$. albicans aderidas; entretanto, os higienizadores de próteses totais disponíveis no mercado (Fittydent e Clinsodent) foram mais efetivos que os produtos domésticos (vinagre e vinagre diluído).

Pellizzaro et al. (2012) analisaram a efetividade da escovação associada a diferentes soluções na eliminação de biofilme de Candida albicans. Foram confeccionados 90 espécimes de resina acrílica, os quais foram esterilizados e inoculados com uma suspensão de $C$. albicans. Após incubação, os espécimes foram aleatoriamente distribuídos em 10 grupos, sendo que 5 grupos foram submetidos à escovação mecânica (90 segundos), com água ou agentes de limpeza (água destilada, dentifrício, digluconato de clorexidina a $2 \%$, hipoclorito de sódio a 1\% e Polident); 4 grupos foram apenas imersos nos agentes de limpeza (90 segundos) e 1 grupo foi imerso em água destilada (90 segundos - controle). A viabilidade celular foi verificada pelo teste XTT. Todos os grupos submetidos à associação da escovação com os agentes de limpeza apresentaram redução efetiva da viabilidade do biofilme, quando comparados à exposição dos espécimes às soluções. A escovação com clorexidina a $2 \%$ e hipoclorito de sódio a $1 \%$ reduziram em $100 \%$ a viabilidade do biofilme. A imersão nos agentes de limpeza resultou em redução na viabilidade celular, com a clorexidina a $2 \%$ sendo a mais efetiva. A utilização de agentes de limpeza em associação ao método de escovação mostrou ser efetivo na remoção do biofilme de $C$. albicans, sendo as soluções de clorexidina e hipoclorito as mais efetivas. 
Ramage et al. (2012), compararam a eficácia de remoção de C.albicans de protocolos de higienização de prótese. Corpos de prova de $1 \mathrm{~cm}^{2}$ de resina acrílica (Chaperlin/Jacobs Ltda) foram preparados segundo as instruções do fabricante e esterilizados com luz ultravioleta por 15 minuto. Após a inoculação de $1 \times 10^{6}$ células de C.albicans $/ \mathrm{mL}$ os corpos de prova foram incubados por 4 horas a $37^{\circ} \mathrm{C}$ e expostos aos seguintes tratamentos higienizadores: (A) Polident - peróxido alcalino - uso diários por 3 minutos, seguindo recomendações do fabricante durante 4 dias ou (B) Polident - Uso intermitente - 1ํ e 4ำ dias, e escovação com dentifrício (Colgate Cavity Protection e escova macia Oral B - durante 2 segundos) no $2^{\circ}$ e $3^{\circ}$ dia. Após cada tratamento os corpos de prova foram transferidos para tubos de ensaio e agitados por 5 minutos em ultrassom. Diluições seriadas foram semeadas e incubadas para contagem das células viáveis após tratamento. Os corpos de prova após os tratamentos foram lavados em PSB, fixados em paraformaldeído $2 \%$, glutaraldeído 2\% e Alciom Blue 0,15\% para a análise em microscopia eletrônica de varredura. A inibição da atividade metabólica do biofilme pelo uso dos higienizadores foi determinada usando XTT e a resposta inflamatória do biofilme pelo teste de Elisa. Para esse teste os corpos de prova após higienização foram colocados em culturas de células, por 245 horas a $37^{\circ} \mathrm{C}$ e $5 \%$ de $\mathrm{CO}_{2}$. Os sobrenadantes das células foram removidos e usados para o teste de Elisa. Os resultados mostraram o tratamento com o Polident inibiu o crescimento de biofilme de C.albicans após 4 horas, sendo mais efetivo o tratamento sequencial que 0 intermitente. $O$ Polident foi mais eficaz que o dentifrício. $O$ teste de Elisa indicou a redução da produção de IL-8, após tratamento com o Polident. Os autores concluíram que a presença de biofilme maduro pode resultar em elevado níveis de inflamação, o qual pode ser controlado por regimes de tratamento químico diário para a manutenção de uma boa saúde oral.

Lucena-Ferreira et al. (2014) investigaram o efeito da exposição diária a um higienizador sobre biofilme de múltiplas espécies. Corpos de prova cilíndricos (10 × $2 \mathrm{~mm}$ ) de resina acrílica (QC-20 PMMA; Dentsply) foram confeccionados segundo instruções do fabricante. Os corpos de prova foram polidos de ambos os lados e a rugosidade de superfície padronizada $(0,32 \pm 0,03)$. Em seguida, foram lavados com água destilada estéril e com ultra-som para remoção dos resíduos da superfície. A esterilização foi realizada com óxido de etileno. Algumas amostras adicionais foram imersas em meio TSB (Trypticase Soy Broth) em condições aeróbicas durante 48 h, 
a fim de confirmar a ausência de contaminação microbiana. A eficácia do processo de esterilização foi confirmada pela ausência de turvação média. Um biofilme misto composto por seis microorganismos, sendo cinco bactérias (Actinomyces naeslundii, Veillonella dispar, Fusobacterium nucleatum,Streptococcus mutans e Streptococcus oralis) e uma levedura (Candida albicans) foi desenvolvido. Todas as cepas foram cultivadas individualmente. Após $15 \mathrm{~h}$ de incubação a $37^{\circ} \mathrm{C}$, alíquotas destas préculturas foram transferidas para um novo tubo e incubadas a $37^{\circ} \mathrm{C}$ durante $7 \mathrm{~h}$. Durante a preparação do inóculo, as bactérias foram incubadas em meio anaeróbico e C. albicans em condições aeróbicas. Após a maturação do biofilme, os corpos de prova foram distribuídos aleatoriamente em grupos controle (sem tratamento) e experimental. No grupo experimental, os corpos de prova foram submetidos a imersões diárias durante 3 minutos em um peróxido alcalino com enzima (Polident 3 Minutos) durante sete dias consecutivos. Decorrido o tempo de imersão, os corpos de prova foram lavados em solução salina, transferidos para tubos contendo $3 \mathrm{~mL}$ de solução salina e colocados no ultra-som $(7 \mathrm{~W})$ por 30 segundos. A suspensão resultante foi utilizada para análise do biofilme. Alíquotas diluídas foram semeadas em meios de cultura específicos. As análise foram feitas nos dias 1, 4, e 7 pelo número de microorganismos e concentrações de polissacarídeos. Análises em microscopia eletrônica de varredura (MEV) e microscopia confocal (CLSM) foram também realizadas. $O$ estudo demonstrou que o total de microrganismos foi menor com uso do Polident, quando comparado ao grupo controle, para todos os períodos avaliados. No entanto, o número total de $C$. albicans aumentou em todos os biofilmes expostos ao higienizador, sendo identificadas hifas nas imagens do MEV E CLSM. A concentração de polissacarídeo foi significativamente maior no grupo experimental após 7 dias. Os autores concluíram que o uso diário de um higienizador de dentadura reduz o número de microrganismos de biofilmes de múltiplas espécies. 
Proposição

(2) 


\section{ProposiçÃo}

O objetivo deste estudo foi avaliar, por meio de estudo in vitro, a ação antimicrobiana de soluções de peróxidos alcalinos frente aos seguintes microrganismos específicos: Candida albicans, Candida glabrata, Staphylococcus aureus, Streptococcus mutans, Bacillus subtilis, Enterococcus faecalis, Pseudomonas aeruginosa e Escherichia coli. 
Material e Métodos 


\section{Material e Métodos}

\subsection{Confecção dos Corpos de Prova}

Foram confeccionados 360 corpos de prova de resina acrílica termopolimerizável (Lucitone 550; Dentsply Ind. Com. Ltda. - Petrópolis - RJ Brasil), a partir de uma matriz metálica circular (15 mm x $3 \mathrm{~mm}$ ) (figura1).

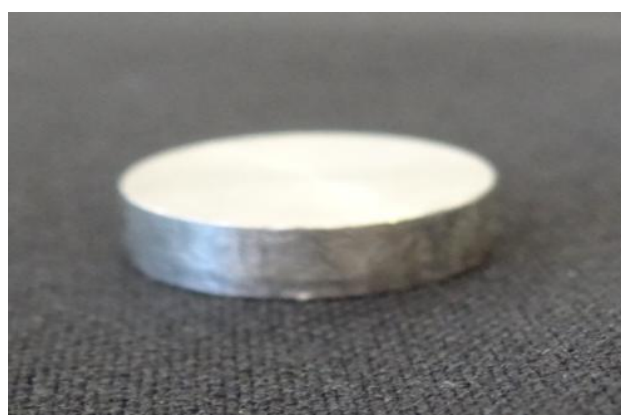

Figura 1: Matriz Metálica Circular

As matrizes foram incluídas em muflas metálicas (Jon; Jon Indústria Brasileira, São Paulo, SP, Brasil), com gesso pedra tipo III (Gesso Rio; Orlando Antônio Bussioli ME, Rio Claro, SP, Brasil). Após a presa do gesso, as muflas foram separadas, as matrizes metálicas removidas (figura 2) e o gesso, isolado (Isolante para Gesso Cel-Lac, SS White Artigos Dentários, Rio de Janeiro, RJ, Brasil). A resina acrílica foi manipulada de acordo com as instruções do fabricante (proporção pó/líquido: $21 \mathrm{~g} / 10 \mathrm{~mL}$ ). Na fase plástica, foi inserida nos moldes (figura 3) e levada a uma prensa hidráulica (Protecni - Protecni Equip. Med., Araraquara, SP, Brasil) para compactação a 1200 kgf, por 30 minutos (figura 4). A polimerização foi realizada pelo método convencional (banho de água) em polimerizadora automática (Termocicler 100 - Oficina de Precisão, Campus da USP de Ribeirão Preto, Ribeirão Preto, SP, Brasil), com imersão em água a $73^{\circ} \mathrm{C}$ por 90 minutos, seguido por estágio de fervura por 30 minutos. Após resfriamento da mufla em temperatura ambiente e demuflagem dos corpos de prova, estes foram imersos em água destilada e mantidos em estufa (Odontobrás Ind. e Com. Equip. Med. Odont. Ltda., Ribeirão Preto, SP, Brasil) a $50^{\circ} \mathrm{C}$ por 24 horas para eliminação do monômero residual. 


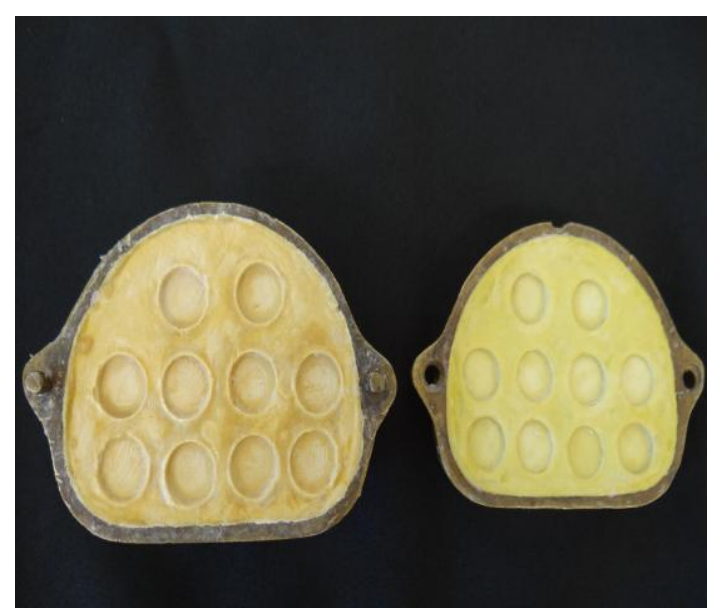

Figura 2: Mufla com matriz em gesso

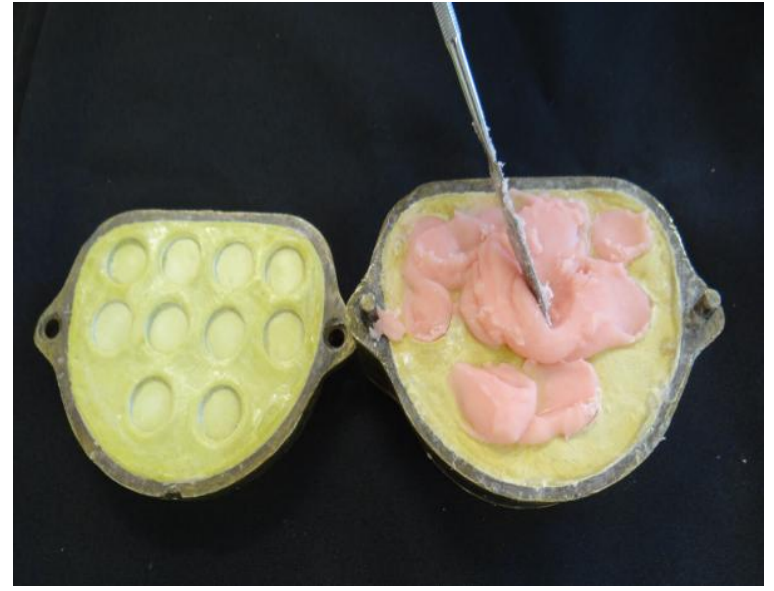

Figura 3: Inserção da resina acrílica nos moldes obtidos

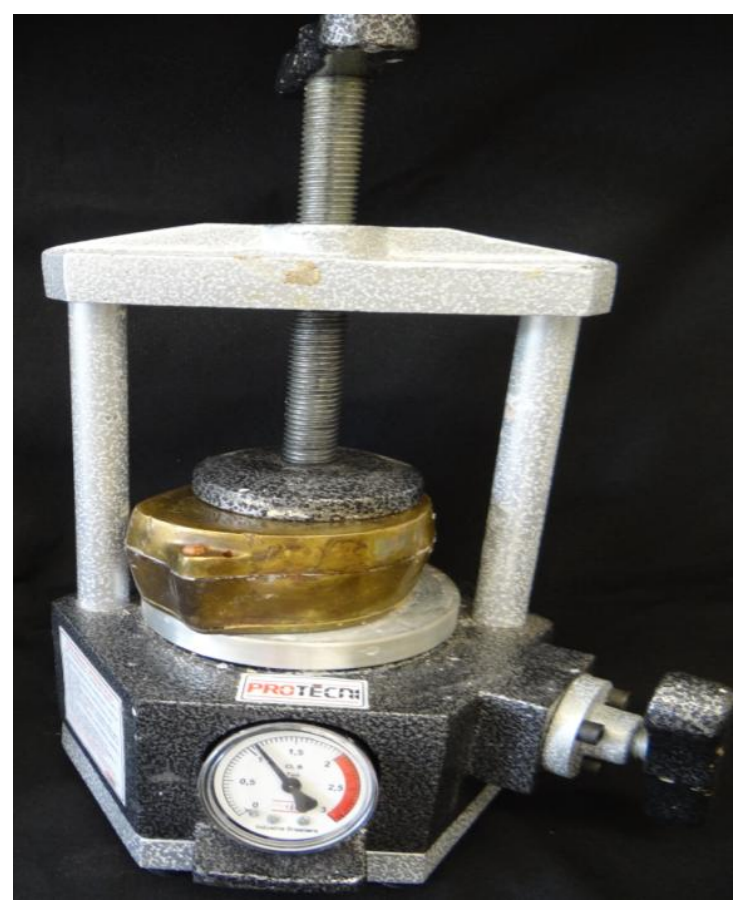

Figura 4: Prensagem da resina acrílica

Os corpos de prova receberam acabamento com fresa multi-laminada (Minicut; Malleifer AS, Ballaiguer, Suíça) (figuras 5A), em micro-motor de baixa rotação (Dabi Atlanti, Ribeirão Preto,SP, Brasil), para remoção dos excessos. Em seguida, cada corpo de prova (figura 5B), foi levado à rugosímetro (Surftest SJ-201P; Mitutoyo Corporation, Tokyo, Japan) para a leitura da rugosidade de superfície de (figura 5C). A rugosidade superficial de cada corpo de prova foi padronizada entre 2,7 e 3,7 $\mu \mathrm{m}$ (Zissis et al, 2000; Panariello 2013) por meio de lixa d'água $n^{\circ} 150$ (Norton Indústria Brasileira, São Paulo, SP, Brasil). Para cada lado do corpo de 
prova foram realizadas três leituras. O valor de $\mathrm{Ra}(\mu \mathrm{m})$ foi calculado como a média de três leituras obtidas.
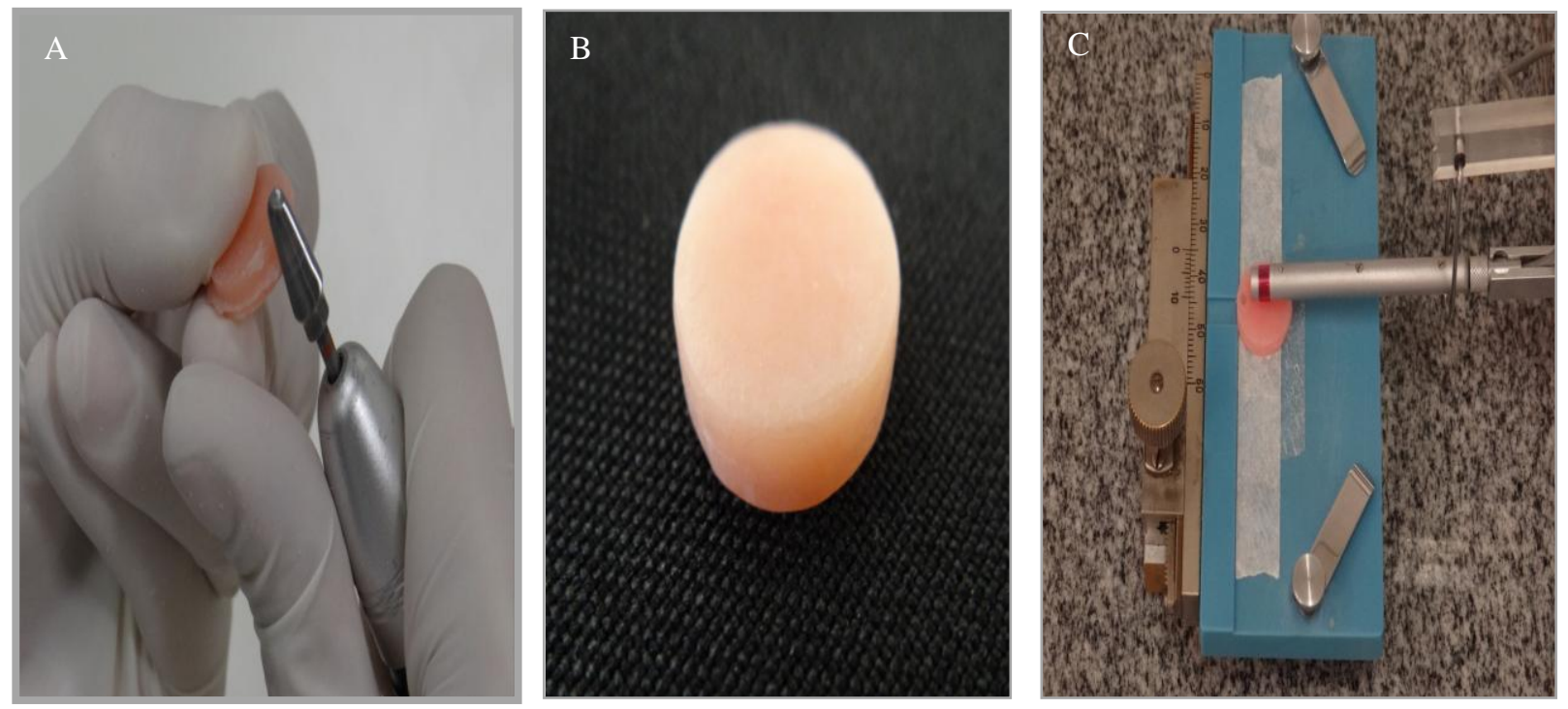

Figura 5. A: Acabamento dos corpos de prova. B: Corpo de prova em resina acrílica. C: Corpo de prova posicionado em rugosímetro

\subsection{Esterilização dos corpos de prova}

Os corpos de prova foram distribuídos aleatoriamente em grupos de 10 , colocados em Béquer com $150 \mathrm{~mL}$ de água destilada e submetidos à esterilização em micro-ondas (Panasonic Perfect, 127 V; 800 W; $2450 \mathrm{MHz}$ ), na potência 8 e tempo de exposição de 6 minutos.

\subsection{Soluções higienizadoras}

Foram empregados três higienizadores à base de peróxidos alcalinos (tabela 1) (figura 6). 
Tabela 1. Higienizadores empregados

\begin{tabular}{|c|c|c|}
\hline Higienizadores & Fabricante & Composição \\
\hline $\begin{array}{c}\text { NitrAdine } \\
\text { Medical Interporous (MI) }\end{array}$ & $\begin{array}{l}\text { MST Laboratories AG, } \\
\text { Vaduz, Liechtenstein }\end{array}$ & $\begin{array}{l}\text { Ácido Cítrico, Lauril sulfato de } \\
\text { sódio, Lactose monohidratada, } \\
\text { Bicarbonato de sódio, Cloreto de } \\
\text { Sódio, Monopersulfate de } \\
\text { potássio de higrogenio }\end{array}$ \\
\hline Efferdent Plus (EF) & $\begin{array}{l}\text { Blacksmith Brands, Inc.; } \\
\text { Tarrytown, NY, USA }\end{array}$ & $\begin{array}{l}\text { Perborato de sódio, EDTA } \\
\text { tetrassódico, Monopersulfato de } \\
\text { potássio }\end{array}$ \\
\hline Corega Tabs (CT) & $\begin{array}{c}\text { Block Drug Company, } \\
\text { Memphis, Tennessee, USA }\end{array}$ & $\begin{array}{l}\text { Bicarbonato de sódio, Acido } \\
\text { Citrico, Carbonato de sódio, } \\
\text { Monopersulfato de potássio, } \\
\text { Perborato de sódio, Benzoato de } \\
\text { sódio, Polifosfato de Sódio, Lauril } \\
\text { sulfoacetato de sódio, Estereato } \\
\text { de sódio, Polietilenoglicol, } \\
\text { Acetato de vinil }\end{array}$ \\
\hline
\end{tabular}

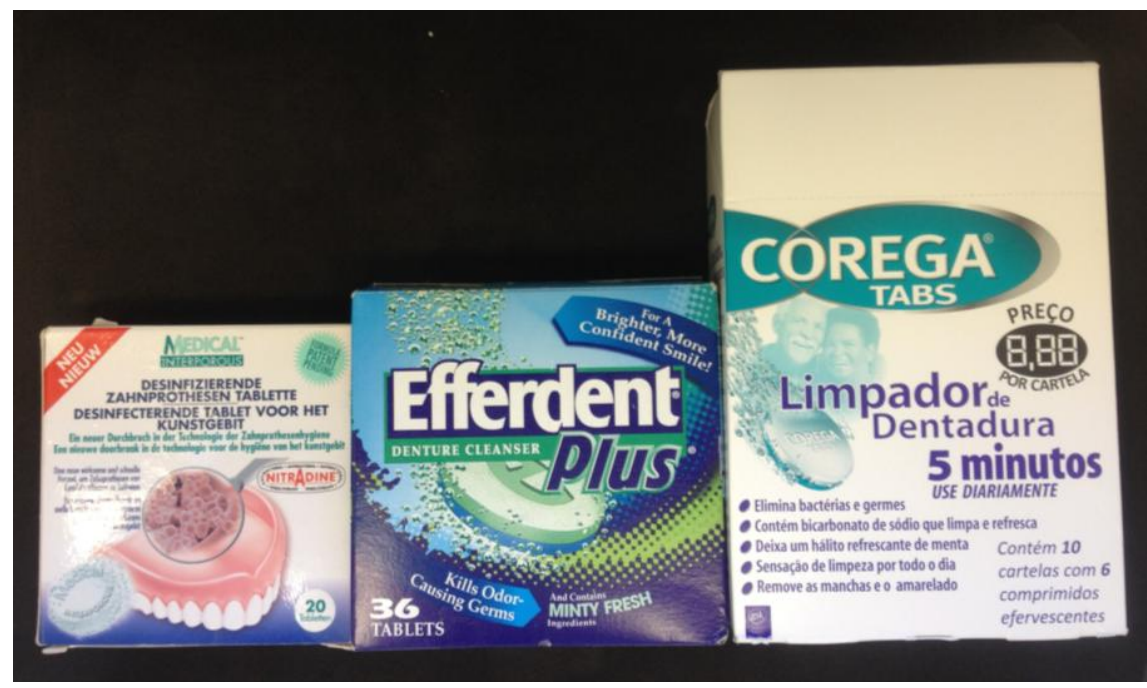

Figura 6: Higienizadores empregados

\subsection{Cepas Microbianas}

Como revelador/indicador da eficácia dos higienizadores, foram utilizadas 8 cepas microbianas (tabela 2), comumente empregadas no controle e monitoramento da atividade antimicrobiana de biocidas e/ou encontradas na boca e em próteses dentárias (Neppelembroek, 2005). 
Tabela 2. Cepas microbianas empregadas

\begin{tabular}{lcc}
\hline \multicolumn{1}{c}{ Microrganismos } & Identificação & $\begin{array}{l}\text { Características } \\
\text { Morfotintoriais }\end{array}$ \\
\hline Candida albicans $(\mathrm{Ca})$ & ATCC 10231 & Leveduras \\
Candida glabrata $(\mathrm{Cg})$ & ATCC 2001 & Leveduras \\
Staphylococcus aureus $(\mathrm{Sa})$ & ATCC 25923 & Cocos gram-positivos \\
Streptococcus mutans $(\mathrm{Sm})$ & ATCC 25175 & Cocos gram-positivos \\
Bacillus subtilis $(\mathrm{Bs})$ & ATCC 6633 & Bacilos gram-positivos \\
Enterococcus faecalis $(\mathrm{Ef})$ & ATCC 29212 & Cocos gram-positivos \\
Escherichia coli $(\mathrm{Ec})$ & ATCC 25922 & Bacilos gram-negativos \\
Pseudomonas aeruginosa $(\mathrm{Pa})$ & ATCC 27853 & Bacilos gram-negativos \\
\hline
\end{tabular}

\subsection{Grupos (Experimentais e Controle)}

Os 360 corpos de prova foram distribuídos em grupos, sendo imersos em béquer contendo $200 \mathrm{~mL}$ das seguintes soluções:

1) Grupo CP (Controle positivo) ( $n=10)$ : PBS (Phosphate buffered saline) por 15 minutos.

2) Grupo MI ( $n=10)$ : Água destilada e 01 pastilha efervescente NitrAdine, Medical Interporous pelo tempo recomendado pelo fabricante (15 minutos) .

3) Grupo EF ( $n=10)$ : Água destilada e 01 pastilha efervescente Efferdent Plus, Anti-bacterial Denture Cleanser pelo tempo recomendado pelo fabricante (15 minutos).

4) Grupo CT ( $n=10)$ : Água destilada e 01 pastilha efervescente Corega Tabs / pelo tempo recomendado pelo fabricante (5 minutos).

5) Grupo CN ( $n=5):$ (Controle negativo): PBS estéril (15 minutos) e sem contaminação.

As temperaturas empregadas foram recomendadas pelo fabricante sendo água água morna $\left(30 \pm 2^{\circ} \mathrm{C}\right)$ para os peróxidos alcalinos e ambiente $\left(23 \pm 2^{\circ} \mathrm{C}\right)$ para os grupos controles. 


\subsection{Meios de cultura empregados para preparação do inoculo microbiano, contaminação e avaliação da esterilidade/contaminação}

Mueller Hinton Broth (HB) (HiMedia Laboratories Pvt. Ltda., Mumbai, Índia): para as cepas $P$. aeruginosa, S. aureus, E. coli e B. subtilis . Modo de preparo: 21,0 $\mathrm{g}$ do meio de cultura desidratado Mueller Hinton Broth (HiMedia Laboratories Pvt. Ltda., Mumbai, Índia) foram adicionados $1000,0 \mathrm{~mL}$ de água destilada e esterilizados em autoclave a $121^{\circ} \mathrm{C}$ por 15 minutos, seguindo instruções do fabricante.

Sabouraud Dextrose Broth (SDB) (HiMedia Laboratories Pvt. Ltda., Mumbai, Índia): para as cepas $C$. albicans e $C$. glabrata. Modo de preparo: $30,0 \mathrm{~g}$ do meio de cultura desidratado Sabouraud Dextrose foram adicionados 1000,0 mL de água destilada e esterilizados em autoclave a $121^{\circ} \mathrm{C}$ por 15 minutos, seguindo as instruções do fabricante.

SB-20 caldo (modificado): para a cepa S. mutans. Modo de preparo: foram adicionados 15,0 g de casitona (HiMedia Laboratories Pvt. Ltda., Mumbai, India), 5,0 $\mathrm{g}$ de extrato de levedura (HiMedia Laboratories Pvt. Ltda., Mumbai, Índia), 0,2 g de cisteína (Vetec Química Fina Ltda., Rio de Janeiro, RJ, Brasil), 0,1 g de sulfito de sódio (Chemco Indústria e Comércio Ltda., Hortolândia, SP, Brasil), 20,0 g de acetado de sódio (Dinâmica Química Contemporânea Ltda., Diadema, SP, Brasil), 200,0 g de sacarose (Dinâmica Química Contemporânea Ltda., Diadema, SP, Brasil) em 1000,0 mL de água destilada, e, em seguida, esterilizados em autoclave a $121^{\circ} \mathrm{C}$ por 15 minutos (Davey; Rogers, 1984).

Tryptone Soya Broth (TSB) (HiMedia Laboratories Pvt. Ltda., Mumbai, Índia): para a cepa $E$. faecalis. Modo de preparo: $30,0 \mathrm{~g}$ do meio de cultura desidratado Tryptone Sya Broth foram adicionados 1000,0 mL de água destilada e esterilizados em autoclave a $121^{\circ} \mathrm{C}$ por 15 minutos, seguindo as instruções do fabricante.

Letheen Broth (LB) (Difco Laboratories Inc., Detroit, Michigan, EUA): Para a avaliação de esterilidade (Grupo CN) e confirmação da contaminação, (Grupo CP). Para cada 25,7 $\mathrm{g}$ do meio de cultura desidratado Letheen Broth foram adicionados $1000,0 \mathrm{~mL}$ de água destilada. O meio de cultura foi distribuído em alíquotas de 10,0 $\mathrm{mL}$ em tubos de ensaio, que posteriormente foram esterilizados em autoclave a $121^{\circ} \mathrm{C}$ por 15 minutos, seguindo as instruções do fabricante. 


\subsection{Contaminação e formação do biofilme}

Para padronização dos inóculos, os microrganismos foram adicionados à $5 \mathrm{~mL}$ de PBS. A turvação da suspensão microbiana foi verificada em espectofotômetro (Bell Photonics, Osasco, SP, Brasil), com a leitura da absorbância entre 0,08 a 0,1 em comprimento de onda de $625 \mathrm{~nm}$, correspondendo a $10^{8}$ e $10^{6}$ células $/ \mathrm{mL}$, para bactérias e leveduras, respectivamente. Em seguida, foi realizada a inoculação do meio de cultura, específico para cada microorganismo, a uma concentração de $1 \%$ (figuras 7 A e 7B). Para confirmação do número celular, alíquotas do inoculo foram semeadas em placas de Petri e incubadas para posterior contagem das colônias.
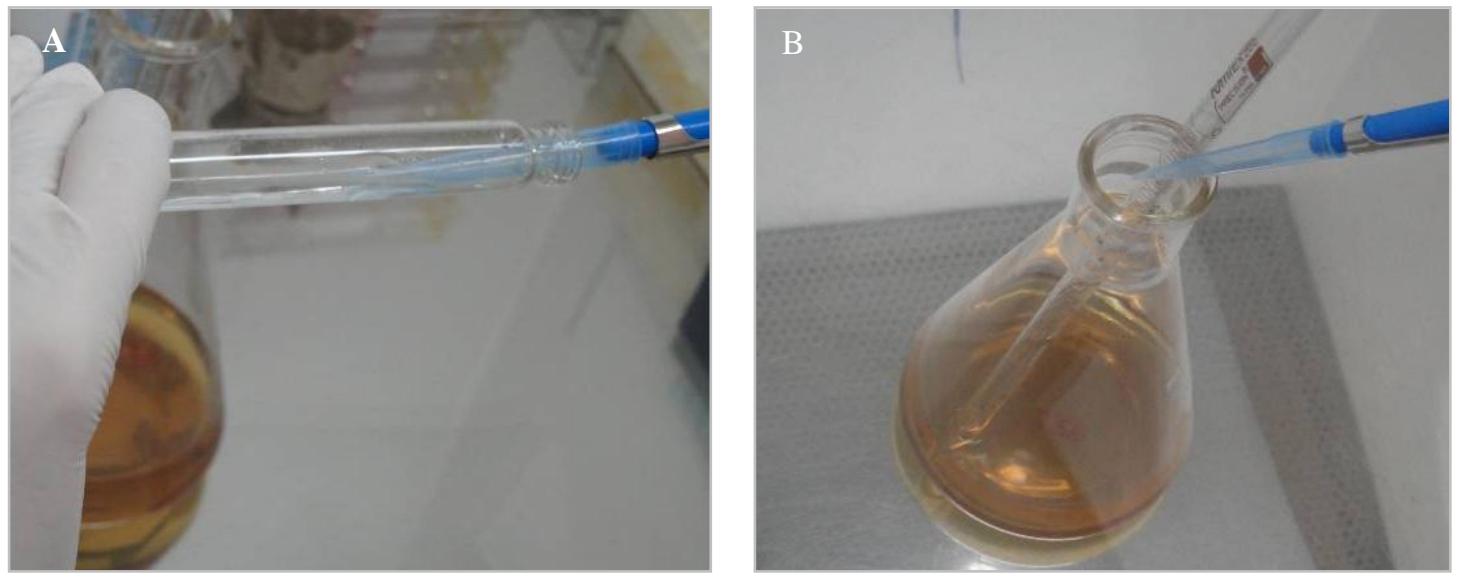

Figuras 7. A-B: Inoculação do meio de cultura.

Em câmara de fluxo laminar (Pachane, Pa 400-ECO, Piracicaba, SP, Brasil), 10 corpos de prova de cada grupo foram distribuídos em placas para cultura de células, com 12 poços (Techno Plastic Products, Trasadingen, Suíça) (figura 8). Para o grupo CN, foram distribuídos 5 corpos de prova.

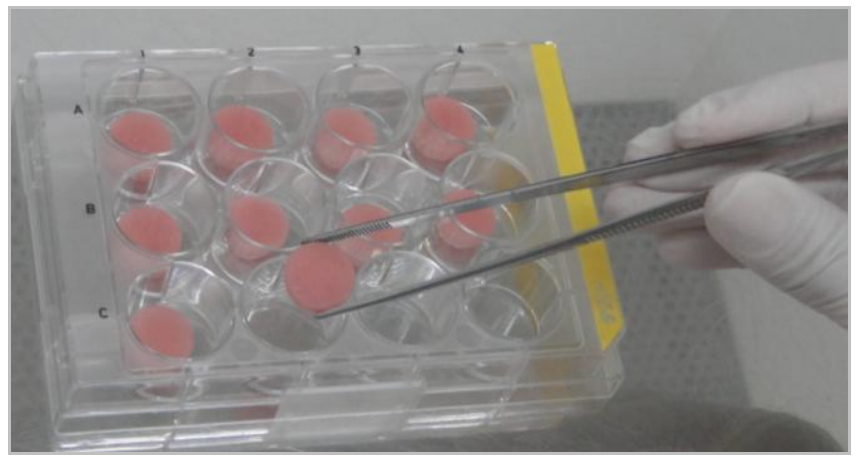

Figura 8: Distribuição dos corpos de prova em placa para cultura de células. 
Para cada orifício da placa de cultura foram adicionados $2 \mathrm{~mL}$ do meio contaminado (figura 9A). Após um período de incubação de 1 hora e 30 minutos, a $37^{\circ} \mathrm{C}$, sob agitação de $75 \mathrm{rpm}$, em estufa bacteriológica (Incubadora Shaker, Mod. CE-320, CienLab, Campinas, SP, Brasil) (figura 9B), cada corpo de prova foi lavado com PBS a fim de remover os microrganismos fracamente aderidos a sua superfície (figura 9C). A seguir, foram acrescentados $2 \mathrm{~mL}$ de meio de cultura estéril em cada poço (figura $9 \mathrm{D}$ ), e as placas foram novamente incubadas a $37^{\circ} \mathrm{C}$, sob agitação, por 48 horas, para maturação do biofilme (figura 9E) (Marra et al., 2012). Para $S$. mutans e $E$. faecalis o período de adesão e maturação do biofilme foi feito em microaerofilia, utilizando jarras de anaerobiose (Jarra Anaeróbia Acrílica 3,5 L, Permution, E. J. Krieger \& Cia. Ltda, Curitiba, PR, Brasil).
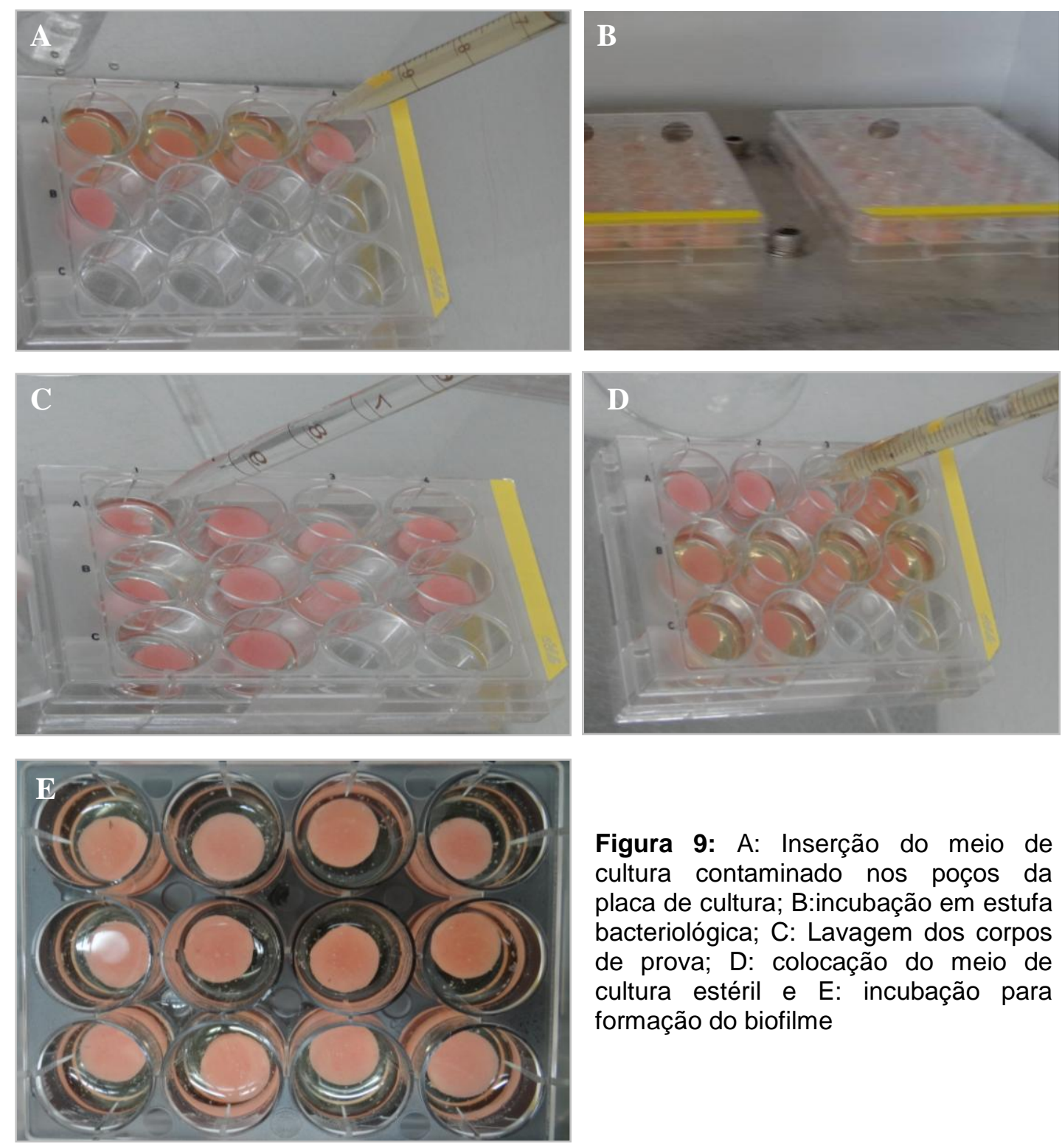

Figura 9: A: Inserção do meio de cultura contaminado nos poços da placa de cultura; B:incubação em estufa bacteriológica; C: Lavagem dos corpos de prova; D: colocação do meio de cultura estéril e $\mathrm{E}$ : incubação para formação do biofilme 


\subsection{Aplicação das Soluções Higienizadoras}

Com pinça esterilizada, cada corpo de prova (figura $10 \mathrm{~A}$ ) foi transferido para uma cesta de aço inoxidável (6 mm comprimento $X 3 \mathrm{~mm}$ de largura e $3 \mathrm{~mm}$ de altura), com 6 repartições de 2,0 X 1,5 mm (figuras $10 \mathrm{~B}$ e $10 \mathrm{C}$ ).
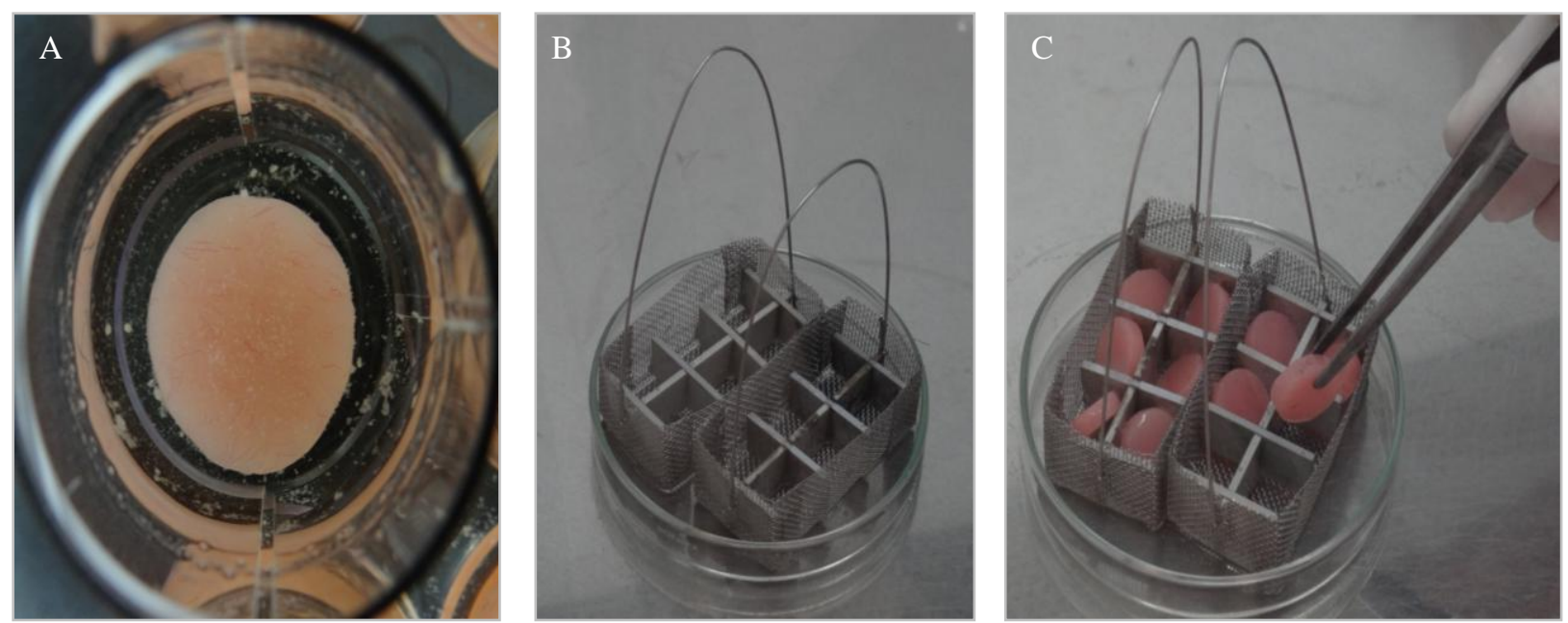

Figura 10: A Biofilme formado; B: Cestas de Aço inoxidável; C: Transferência dos corpos de prova

Para cada grupo experimental (MI, EF e CT) (figura 11 A) a cesta foi imersa em contêiner com $200 \mathrm{~mL}$ de água destilada esterilizada a $30 \pm 2^{\circ} \mathrm{C}$ e em seguida, foi adicionada 1 pastilha efervescente (figura $11 \mathrm{~B}$ ). A imersão foi feita pelo tempo indicado pelo fabricante. Para os grupos $\mathrm{CP}$ e $\mathrm{CN}$, cada corpo de prova foi transferido para uma cesta esterilizada, a qual foi imersa em contêiner com $200 \mathrm{~mL}$ de água destilada esterilizada a $23 \pm 2^{\circ} \mathrm{C} \stackrel{\circ}{ } \mathrm{C}$ por 15 minutos.

Decorrido o período de imersão, procedeu-se o procedimento de lavagem (5 minutos) dos corpos de prova transferindo as cestas para outros contêineres com $200 \mathrm{~mL}$ de água destilada (figura $11 \mathrm{C}$ ). A seguir, cada grupo foi transferido para uma placa com água destilada e enxaguado por três vezes, com o objetivo de remover possíveis resquícios das soluções higienizadoras utilizadas. Após o enxague, cada corpo de prova foi transferido para um tubo de ensaio de vidro contendo $10 \mathrm{~mL}$ de meio Letheen, para avaliação da contaminação e/ou esterilidade. 

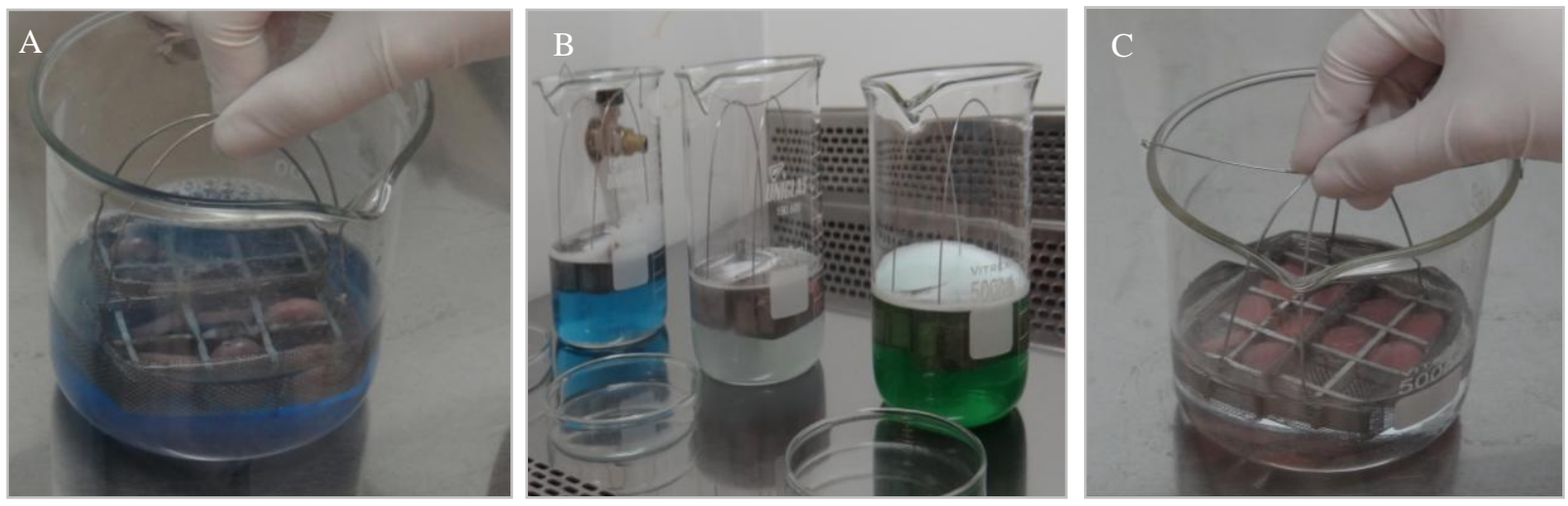

Figura 11: A: Imersão em solução higienizadora; B: Soluções higienizadoras; C: Lavagem dos corpos de prova

\subsection{Semeadura}

\subsubsection{Meios de cultura empregados}

Mueller Hinton Agar (MHA) (HiMedia Laboratories Pvt. Ltda., Mumbai, Índia): para as cepas $P$. aeruginosa, $S$. aureus, E. coli e B. subtilis. Modo de preparo: para cada $38,0 \mathrm{~g}$ do meio de cultura desidratado Mueller Hinton foram adicionados $1000,0 \mathrm{~mL}$ de água destilada e esterilizados em autoclave a $121^{\circ} \mathrm{C}$ por 15 minutos, seguindo as instruções do fabricante.

Sabouraud Dextrose Agar (SDA) (HiMedia Laboratories Pvt. Ltda., Mumbai, Índia): para as cepas C. albicans e C. glabrata. Modo de preparo: para cada 65,0 g do meio de cultura desidratado Sabouraud Dextrose Agar foram adicionados 1000,0 $\mathrm{mL}$ de água destilada e, em seguida, esterilizados em autoclave a $121^{\circ} \mathrm{C}$ por 15 minutos, seguindo instruções do fabricante.

SB-20 ágar (modificado): para a cepa S. mutans. Modo de preparo: para o preparo, foram adicionados 15,0 g de casitona (HiMedia Laboratories Pvt. Ltda., Mumbai, India), 5,0 g de extrato de levedura (HiMedia Laboratories Pvt. Ltda., Mumbai, Índia), 0,2 g de cisteína (Vetec Química Fina Ltda., Rio de Janeiro, RJ, Brasil), 0,1 g de sulfito de sódio (Chemco Indústria e Comércio Ltda., Hortolândia, SP, Brasil), 20,0 g de acetado de sódio (Dinâmica Química Contemporânea Ltda., Diadema, SP, Brasil), 200,0 g de sacarose (Dinâmica Química Contemporânea Ltda., Diadema, SP, Brasil) e 15,0 g de Agar bacteriológico (HiMedia Laboratories Pvt. Ltda., Mumbai, Índia) em 1000,0 mL de água destilada, e, em seguida, esterilizados em autoclave a $121^{\circ} \mathrm{C}$ por 15 minutos (Davey; Rogers, 1984). 
Tryptone Soya Agar (TSA) (HiMedia Laboratories Pvt. Ltda., Mumbai, Índia): para a cepa $E$. faecalis. Modo de preparo: para cada $40,0 \mathrm{~g}$ do meio de cultura desidratado Tryptone Soya Agar, foram adicionados 1000,0 mL de água destilada e esterilizados em autoclave a $121^{\circ} \mathrm{C}$ por 15 minutos, seguindo instruções do fabricante.

\subsubsection{Semeadura dos corpos de prova}

Os tubos de ensaio contendo os corpos de prova foram mantidos por 20 minutos em cuba de ultrassom (Altsonic, Clean 9CA, Ribeirão Preto, SP, Brasil) visando o desprendimento de células microbianas (figura 12).

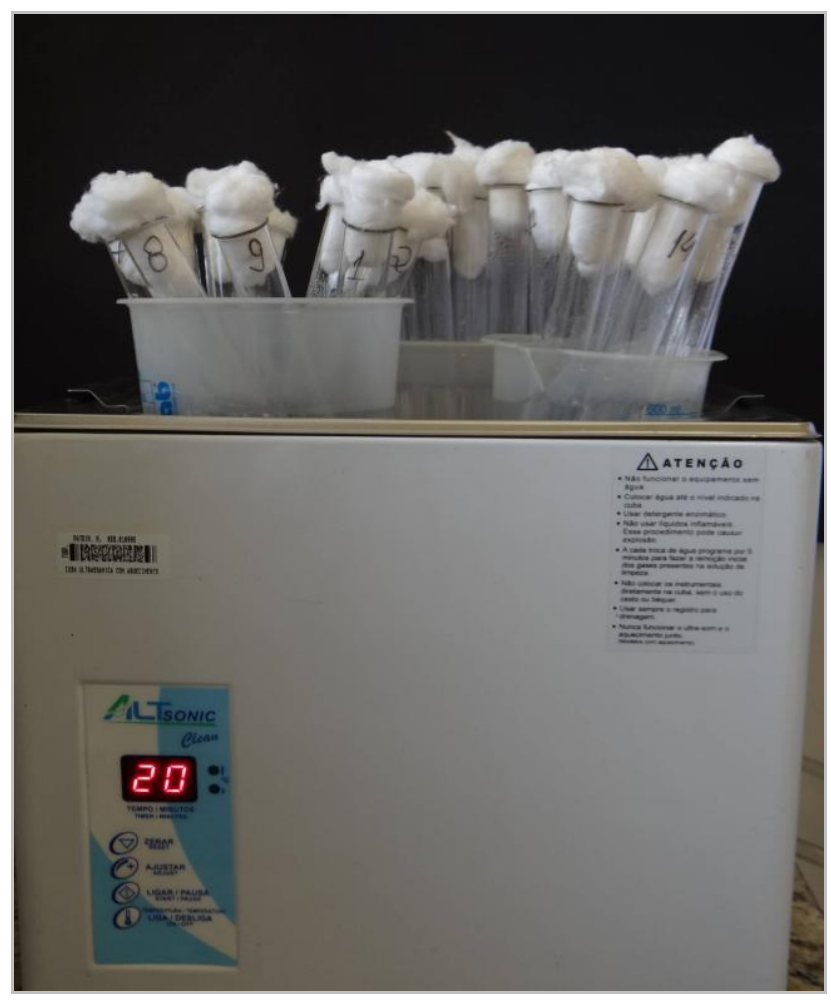

Figura 12: Tubos de ensaio colocados em ultrassom

Em seguida, para a semeadura, os tubos de ensaio foram individualmente agitados em agitador mecânico (Phoenix® - AP56, Ind. E Com. de Equip. Científicos Ltda, Araraquara, SP, Brasil) (figura 13), durante 15 segundos e uma alíquota de 25 $\mu \mathrm{L}$ da suspensão foi semeada $\left(10^{\circ}\right)$ em placa de Petri, contendo os meios de culturas específicos. Em seguida, realizou-se diluições seriadas de $10^{-1}$ a $10^{-3}$, sendo as alíquotas de cada diluição também semeadas em placas de Petri (figura 14 A a $14 \mathrm{C}$ ) e incubadas a $37^{\circ} \mathrm{C}$ por 24 horas em estufa microbiológica (figura $15 \mathrm{~A}$ ). As incubações das cepas $S$. mutans e da $E$. faecalis foram realizadas em microaerofilia com utilização de jarras anaeróbias acrílicas de 3,5L (figura 16). 
Após finalizarem as semeaduras, os tubos de ensaios contendo os corpos de prova foram incubados a $37^{\circ} \mathrm{C}$ por até 28 dias para avaliação de esterilidade e confirmação da contaminação (figura 17).

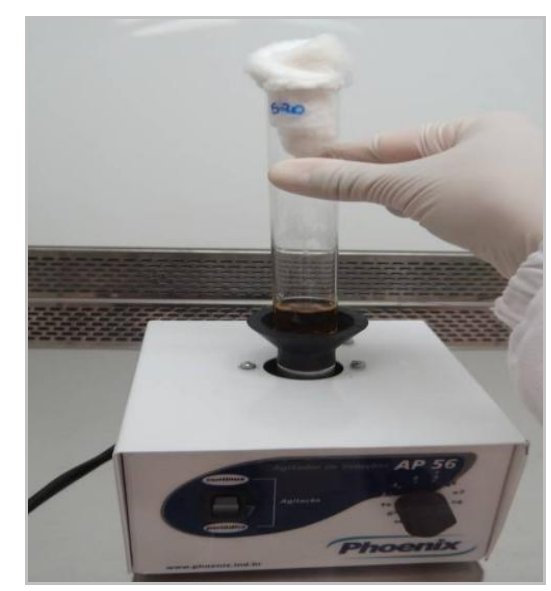

Figura 13: Agitação dos tubos de ensaio
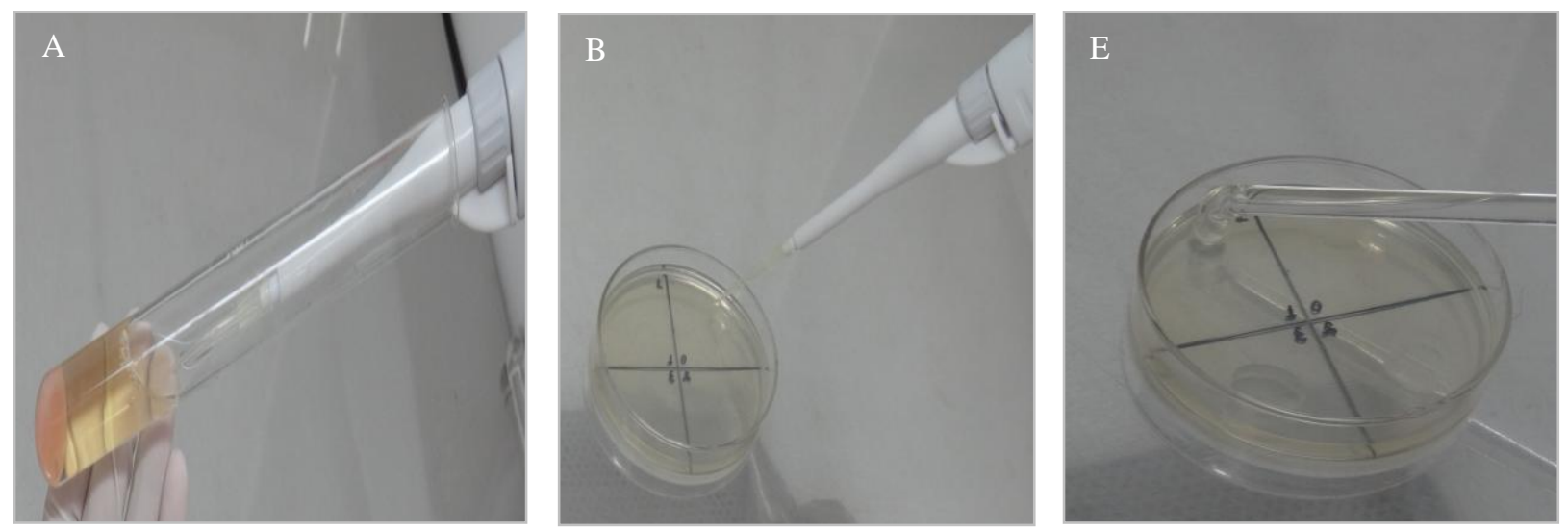

Figura 14: A: Preparo da diluição; B: Diluição $10^{\circ}$ e C: semeadura. 


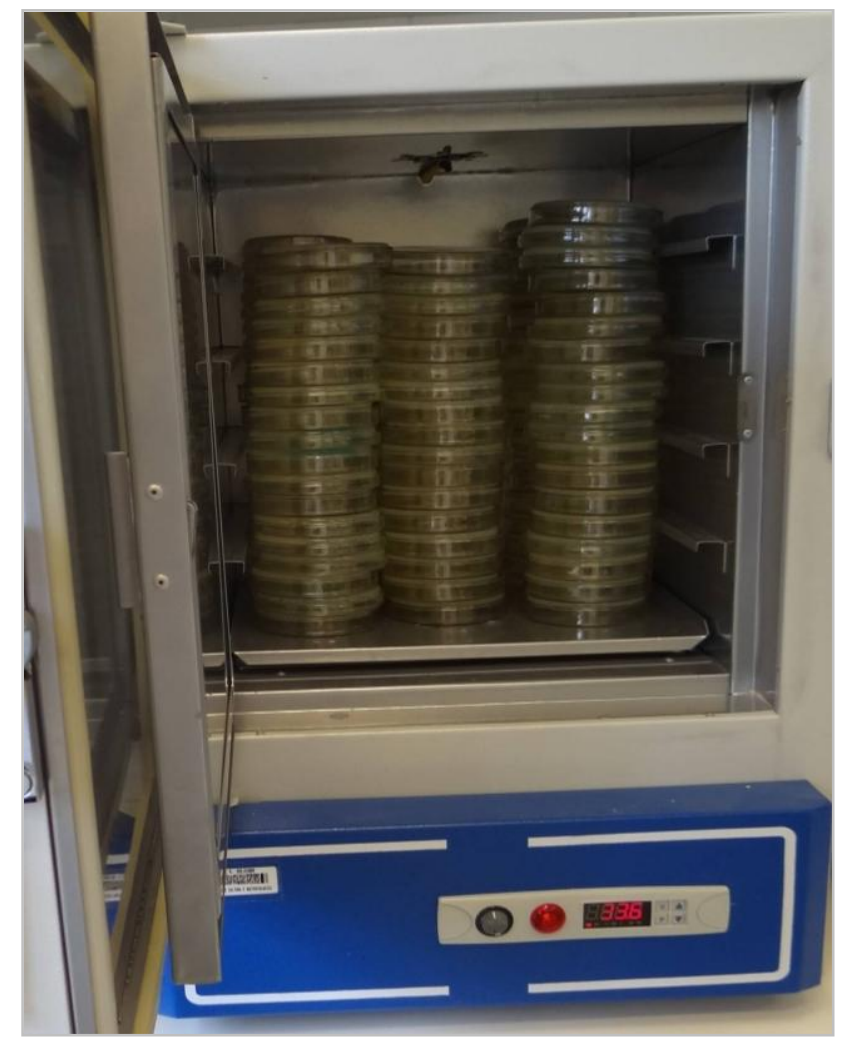

Figura 15: Incubação das placas

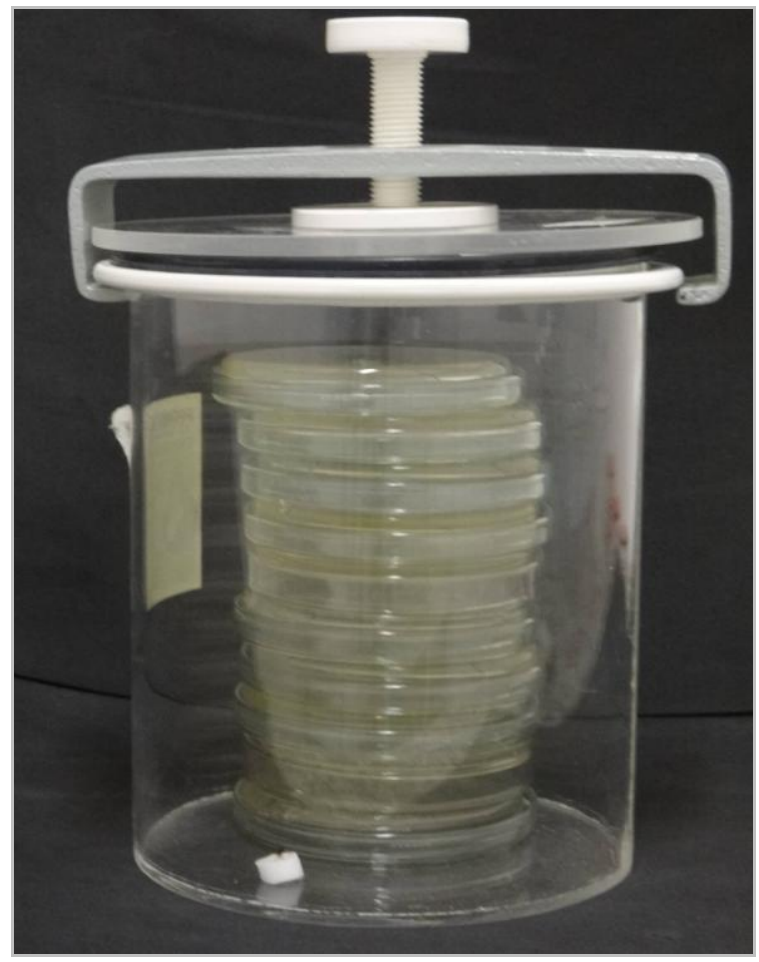

Figura 16: Incubação em microaerofilia 


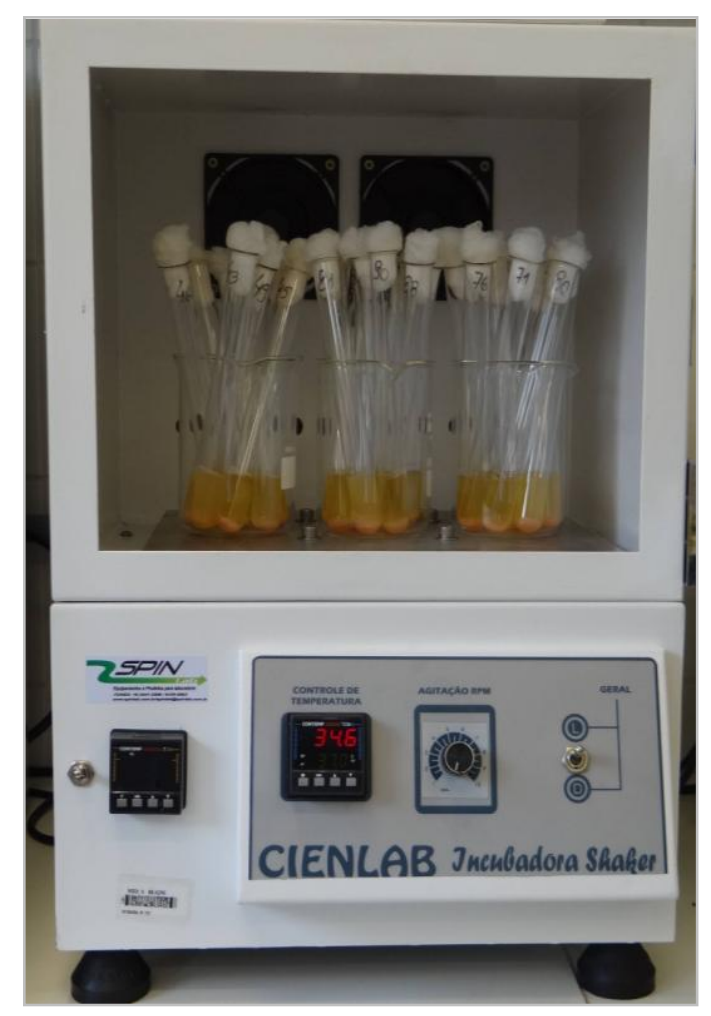

Figura 17: Incubação dos tubos.

Após incubação com o auxílio de uma lupa microscópica (Nikon, modelo 86786, Tókio, Japão), o número de colônias de cada duplicata foi contado e os valores de UFC/mL calculados, por meio da fórmula:

$\mathrm{UFC} / \mathrm{mL}=\underline{\mathrm{n}^{\circ} \text { de colônias } \times 10^{\mathrm{n}}}$, sendo: q n: valor absoluto da diluição (0, 1, 2 ou 3);

q: quantidade, em $\mathrm{mL}$, pipetada para cada

diluição quando da semeadura.

Os valores de UFC/mL obtidos foram transformados de acordo com a fórmula $\log 10($ UFC + 1). Verificada a distribuição não normal dos dados (Teste de ShapiroWilk), realizou-se teste de Kruskal-Wallis, seguido teste de Dunn $(\alpha=0,05)$. 
Resultados 


\section{REsultados}

\subsection{Análise de esterilidade}

A Tabela 3 apresenta os resultados da turvação dos meios de cultura dos tubos de ensaio contendo os corpos de prova após a imersão e posterior incubação.

Tabela 3. Turvação dos tubos de ensaio contendo os corpos de prova após a imersão em soluções à base de peróxidos alcalinos e incubação.

\begin{tabular}{ccccccccc}
\hline \multirow{2}{*}{ Grupos } & \multicolumn{9}{c}{ Microrganismos } \\
& Pa & Ca & Bs & As & Sm & Cg & Ec & Ef \\
\hline CP & + & + & + & + & + & + & + & + \\
MI & + & + & + & + & + & + & + & + \\
EF & + & + & + & + & + & + & + & + \\
CT & + & + & + & + & + & + & + & + \\
CN & - & - & - & - & - & - & - & - \\
\hline
\end{tabular}

Os microrganismos: Pa: Pseudomonas aeruginosa; Ca: Candida albicans; Bs: Bacillus subtilis; Sa: Staphylococcus aureus; Sm: Streptococcus mutans; Cg: Candida glabrata; Ec: Echerichia coli; Ef: Enterococcus faecalis. I (+): indica turvação do meio, (-) indica ausência de turvação.

Os resultados mostraram turvação dos meios de cultura para todos os grupos experimentais (MI, EF, CT) e grupo controle positivo (CP), indicando crescimento de todas as cepas avaliadas. A esterilidade dos corpos de prova do grupo CN foi comprovada pela ausência de turvação.

\subsection{Análise Antimicrobiana}

As tabelas de 4 a 11 apresentam os resultados (UFC/mL) de cada cepa avaliada.

Tabela 4 . C.albicans - Total de UFC/mL, em log $(\mathrm{UFC}+1)$

\begin{tabular}{ccccc}
\hline Espécimes & Grupo CP & Grupo MI & Grupo EF & Grupo CT \\
\hline $\mathbf{1}$ & 4,06 & 0,00 & 3,25 & 3,49 \\
$\mathbf{2}$ & 3,38 & 0,00 & 2,80 & 2,85 \\
$\mathbf{3}$ & 3,30 & 1,61 & 3,06 & 5,74 \\
$\mathbf{4}$ & 3,68 & 0,00 & 3,13 & 2,71 \\
$\mathbf{5}$ & 3,70 & 0,00 & 2,08 & 1,61 \\
$\mathbf{6}$ & 3,53 & 4,58 & 1,90 & 2,08 \\
$\mathbf{7}$ & 3,50 & 0,00 & 3,33 & 3,01 \\
$\mathbf{8}$ & 4,09 & 2,71 & 2,60 & 2,80 \\
$\mathbf{9}$ & 3,77 & 2,90 & 3,81 & 2,74 \\
$\mathbf{1 0}$ & 3,71 & 1,61 & 3,31 & 3,23 \\
\hline
\end{tabular}


Tabela 5. C.glabrata - Total de UFC/mL, em log (UFC +1)

\begin{tabular}{ccccc}
\hline Espécimes & Grupo CP & Grupo MI & Grupo EF & Grupo CT \\
\hline $\mathbf{1}$ & 5,78 & 0,00 & 3,31 & 4,31 \\
$\mathbf{2}$ & 5,78 & 0,00 & 3,18 & 4,06 \\
$\mathbf{3}$ & 6,24 & 1,61 & 3,83 & 4,88 \\
$\mathbf{4}$ & 5,86 & 0,00 & 3,73 & 4,06 \\
$\mathbf{5}$ & 5,82 & 3,40 & 3,30 & 4,57 \\
$\mathbf{6}$ & 6,13 & 3,04 & 2,85 & 4,58 \\
$\mathbf{7}$ & 5,96 & 0,00 & 3,57 & 4,42 \\
$\mathbf{8}$ & 5,78 & 4,04 & 4,17 & 4,51 \\
$\mathbf{9}$ & 6,00 & 0,00 & 3,26 & 4,30 \\
$\mathbf{1 0}$ & 5,02 & 0,00 & 3,14 & 4,26 \\
\hline
\end{tabular}

Tabela 6. S.aureus - Total de UFC/mL, em log (UFC +1)

\begin{tabular}{ccccc}
\hline Espécimes & Grupo CP & Grupo MI & Grupo EF & Grupo CT \\
\hline $\mathbf{1}$ & 5,07 & 0,00 & 4,13 & 3,64 \\
$\mathbf{2}$ & 4,96 & 0,00 & 4,29 & 3,45 \\
$\mathbf{3}$ & 4,42 & 3,14 & 4,30 & 5,02 \\
$\mathbf{4}$ & 5,42 & 0,00 & 4,13 & 3,70 \\
$\mathbf{5}$ & 5,34 & 0,00 & 3,91 & 3,92 \\
$\mathbf{6}$ & 5,57 & 1,61 & 3,66 & 4,06 \\
$\mathbf{7}$ & 5,44 & 0,00 & 4,27 & 2,55 \\
$\mathbf{8}$ & 5,43 & 1,61 & 3,65 & 4,07 \\
$\mathbf{9}$ & 5,37 & 0,00 & 3,85 & 4,19 \\
$\mathbf{1 0}$ & 5,17 & 0,00 & 4,14 & 3,23 \\
\hline
\end{tabular}

Tabela 7. S.mutans - Total de UFC/mL, em log $(U F C+1)$

\begin{tabular}{ccccc}
\hline Espécimes & Grupo CP & Grupo MI & Grupo EF & Grupo CT \\
\hline $\mathbf{1}$ & 5,06 & 2,08 & 1,61 & 4,86 \\
$\mathbf{2}$ & 3,85 & 0,00 & 2,71 & 4,04 \\
$\mathbf{3}$ & 4,85 & 0,00 & 2,44 & 4,15 \\
$\mathbf{4}$ & 5,09 & 1,90 & 1,61 & 4,76 \\
$\mathbf{5}$ & 4,64 & 1,61 & 3,00 & 4,78 \\
$\mathbf{6}$ & 3,63 & 0,00 & 0,00 & 4,74 \\
$\mathbf{7}$ & 5,49 & 0,00 & 2,55 & 5,32 \\
$\mathbf{8}$ & 5,26 & 0,00 & 0,00 & 4,73 \\
$\mathbf{9}$ & 5,40 & 0,00 & 0,00 & 4,24 \\
$\mathbf{1 0}$ & 5,00 & 0,00 & 2,38 & 4,29 \\
\hline
\end{tabular}


Tabela 8., B.subtilis - Total de UFC/mL, em log (UFC +1)

\begin{tabular}{ccccc}
\hline Espécimes & Grupo CP & Grupo MI & Grupo EF & Grupo CT \\
\hline $\mathbf{1}$ & 3,07 & 0,00 & 4,26 & 0,00 \\
$\mathbf{2}$ & 3,60 & 1,61 & 4,44 & 3,71 \\
$\mathbf{3}$ & 3,90 & 0,00 & 3,98 & 1,90 \\
$\mathbf{4}$ & 3,49 & 0,00 & 4,21 & 0,00 \\
$\mathbf{5}$ & 2,08 & 0,00 & 0,00 & 0,00 \\
$\mathbf{6}$ & 3,60 & 0,00 & 1,61 & 1,61 \\
$\mathbf{7}$ & 3,68 & 0,00 & 0,00 & 0,00 \\
$\mathbf{8}$ & 3,77 & 4,01 & 3,50 & 0,00 \\
$\mathbf{9}$ & 3,74 & 2,98 & 1,61 & 0,00 \\
$\mathbf{1 0}$ & 3,71 & 4,42 & 3,72 & 0,00 \\
\hline
\end{tabular}

Tabela 9. E. faecalis - Total de UFC/mL, em log $(\mathrm{UFC}+1)$

\begin{tabular}{ccccc}
\hline Espécimes & Grupo CP & Grupo MI & Grupo EF & Grupo CT \\
\hline $\mathbf{1}$ & 6,28 & 0,00 & 5,09 & 5,64 \\
$\mathbf{2}$ & 5,45 & 0,00 & 4,70 & 4,24 \\
$\mathbf{3}$ & 5,68 & 0,00 & 4,13 & 6,00 \\
$\mathbf{4}$ & 5,33 & 0,00 & 4,30 & 5,03 \\
$\mathbf{5}$ & 5,54 & 1,90 & 3,86 & 3,41 \\
$\mathbf{6}$ & 5,72 & 0,00 & 3,36 & 4,34 \\
$\mathbf{7}$ & 5,57 & 1,61 & 3,94 & 4,60 \\
$\mathbf{8}$ & 5,47 & 0,00 & 4,72 & 4,64 \\
$\mathbf{9}$ & 5,67 & 0,00 & 3,07 & 4,62 \\
$\mathbf{1 0}$ & 5,24 & 0,00 & 3,64 & 6,55 \\
\hline
\end{tabular}

Tabela 10. E.coli - Total de UFC/mL, em log (UFC +1)

\begin{tabular}{ccccc}
\hline Espécimes & Grupo CP & Grupo MI & Grupo EF & Grupo CT \\
\hline $\mathbf{1}$ & 4,52 & 0,00 & 0,00 & 0,00 \\
$\mathbf{2}$ & 4,36 & 3,52 & 0,00 & 2,30 \\
$\mathbf{3}$ & 4,44 & 0,00 & 0,00 & 0,00 \\
$\mathbf{4}$ & 4,49 & 0,00 & 1,61 & 0,00 \\
$\mathbf{5}$ & 4,57 & 0,00 & 0,00 & 1,61 \\
$\mathbf{6}$ & 4,45 & 0,00 & 1,61 & 0,00 \\
$\mathbf{7}$ & 4,42 & 0,00 & 0,00 & 0,00 \\
$\mathbf{8}$ & 3,96 & 0,00 & 2,08 & 0,00 \\
$\mathbf{9}$ & 4,47 & 0,00 & 0,00 & 0,00 \\
$\mathbf{1 0}$ & 4,44 & 0,00 & 0,00 & 0,00 \\
\hline
\end{tabular}


Tabela 11. $P$. aeruginosa - Total de UFC/mL, em log (UFC +1)

\begin{tabular}{ccccc}
\hline Espécimes & Grupo CP & Grupo MI & Grupo EF & Grupo CT \\
\hline $\mathbf{1}$ & 5,88 & 0,00 & 0,00 & 4,46 \\
$\mathbf{2}$ & 5,97 & 0,00 & 0,00 & 3,34 \\
$\mathbf{3}$ & 6,18 & 0,00 & 0,00 & 2,20 \\
$\mathbf{4}$ & 5,00 & 0,00 & 1,61 & 3,27 \\
$\mathbf{5}$ & 5,46 & 1,61 & 0,00 & 2,38 \\
$\mathbf{6}$ & 5,37 & 0,00 & 0,00 & 2,50 \\
$\mathbf{7}$ & 5,72 & 0,00 & 2,44 & 4,32 \\
$\mathbf{8}$ & 5,82 & 0,00 & 0,00 & 4,17 \\
$\mathbf{9}$ & 5,01 & 0,00 & 4,24 & 4,14 \\
$\mathbf{1 0}$ & 5,87 & 0,00 & 0,00 & 3,09 \\
\hline
\end{tabular}

\subsection{Análise Estatística}

As tabelas 12,13 e 14 apresentam os resultados da análise estatística para leveduras, gram positivos e gram negativos, respectivamente.

Tabela 12. UFC/mL em log 10 (UFC + 1) - Medianas (e intervalo de confiança 95\%) e valores do teste Kruskal-Wallis

\begin{tabular}{|c|c|c|}
\hline Leveduras/grupos & C. albicans & C. glabrata \\
\hline $\begin{array}{l}\mathrm{CP} \\
\mathrm{MI} \\
\mathrm{EF} \\
\mathrm{CT}\end{array}$ & $\begin{array}{c}3,69(3,49 \text { a } 3,86)^{a} \\
0,81(0,17 \text { a } 2,51)^{b} \\
3,10(2,50 \text { a } 3,35)^{a, b} \\
2,83(2,24 \text { a } 3,81)^{a, b}\end{array}$ & $\begin{array}{l}5,84(5,60 \text { a } 6,07)^{a} \\
0,00(0,01 \text { a } 2,40)^{c} \\
3,31(3,16 \text { a } 3,71)^{b, c} \\
4,37(4,21 \text { a } 4,58)^{a, b}\end{array}$ \\
\hline $\begin{array}{c}\text { Valor de P } \\
\text { (Kruskal-Wallis) }\end{array}$ & $<0,001$ & $<0,001$ \\
\hline
\end{tabular}

CP (Controle Positivo), MI (NitrAdine, Medical Interporous), EF (Efferdente Plus), CT (Corega Tabs)

Para cada coluna, letras diferentes indicam diferenças significativas $(p<0,05)$

Os resultados mostraram diferença significativa entre os grupos ( $\mathrm{Ca} p<0,001$ e $\mathrm{Cg}$ p<0,001) havendo redução significante do número de UFC de Ca (Grupo MI) e $\mathrm{Cg}$ (Grupo MI), quando comparado ao grupo controle. 
Tabela 13. UFC/mL em log 10 (UFC + 1) - Medianas (e intervalo de confiança 95\%) e valores do teste Kruskal-Wallis

\begin{tabular}{|c|c|c|c|c|}
\hline $\begin{array}{l}\text { Gram- } \\
\text { positivos/ } \\
\text { grupos }\end{array}$ & S.aureus & S. mutans & B.subtilis & E.faecalis \\
\hline $\begin{array}{l}\text { CP } \\
\text { MI } \\
\text { EF } \\
\text { CT }\end{array}$ & $\begin{array}{c}5,36(4,98 \text { a } 5,46)^{\mathrm{a}} \\
0,00(-0,15 \text { a } 1,43)^{\mathrm{c}} \\
4,13(3,85 \text { a } 4,21)^{\mathrm{a}, \mathrm{b}} \\
3,81(3,32 \text { a } 4,25)^{\mathrm{b}, \mathrm{c}}\end{array}$ & $\begin{array}{l}5,03(4,38 \text { a } 5,28)^{\mathrm{a}} \\
0,00(-0,09 \text { a } 1,21)^{\mathrm{b}} \\
2,00(0,77 \text { a } 2,49)^{\mathrm{b}} \\
4,74(4,31 \text { a } 4,88)^{\mathrm{a}}\end{array}$ & $\begin{array}{l}3,64(3,08 \text { a } 3,85)^{\mathrm{a}} \\
0,00(-0,01 \text { a } 2,61)^{\mathrm{a}, \mathrm{b}} \\
3,61(1,47 \text { a } 3,99)^{\mathrm{a}, \mathrm{b}} \\
0,00(-0,19 \text { a } 1,64)^{\mathrm{b}}\end{array}$ & $\begin{array}{l}5,56(5,39 \text { a } 5,80)^{a} \\
0,00(-0,18 \text { a } 0,88)^{c} \\
4,04(3,62 \text { a } 4,54)^{b, c} \\
4,63(4,25 \text { a } 5,57)^{a, b}\end{array}$ \\
\hline $\begin{array}{l}\text { Valor de P } \\
\text { (Kruskal- } \\
\text { Wallis) }\end{array}$ & $<0,001$ & $<0,001$ & 0,005 & $<0,001$ \\
\hline
\end{tabular}

Os resultados mostraram diferença significativa entre os grupos para as bactérias gram-positivas ( $S$. mutans $p<0,001$, $S$. aureus $p<0,001$, B. subtilis $p=0,005$ e E. faecalis $\mathrm{p}<0,001$ ) havendo redução significante do UFC de $S$. aureus (Grupo MI), de S. mutans (Grupos MI e EF), de B. subtilis (Grupo CT) e de E.faecalis (Grupo MI) quando comparados ao grupo controle.

Tabela 14. UFC/mL em log 10 (UFC + 1) - Medianas (e intervalo de confiança 95\%) e valores do teste Kruskal-Wallis

\begin{tabular}{|c|c|c|}
\hline Gram-negativos/Grupos & E.coli & P. aeruginosa \\
\hline $\begin{array}{l}\mathrm{CP} \\
\mathrm{MI} \\
\mathrm{EF} \\
\mathrm{CT} \\
\end{array}$ & $\begin{array}{l}4,45(4,29 \text { a } 4,53)^{\mathrm{a}} \\
0,00(-0,44 \text { a } 1,15)^{\mathrm{b}} \\
0,00(-0,09 \text { a } 1,15)^{\mathrm{b}} \\
0,00(-0,21 \text { a } 0,99)^{\mathrm{b}}\end{array}$ & $\begin{array}{l}5,77(5,34 \text { a } 5,92)^{\mathrm{a}} \\
0,00(-0,20 \text { a } 0,53)^{\mathrm{c}} \\
0,00(-0,23 \text { a } 1,89)^{\mathrm{b}, \mathrm{c}} \\
3,31(2,78 \text { a } 4,00)^{\mathrm{a}, \mathrm{b}}\end{array}$ \\
\hline $\begin{array}{c}\text { Valor de P (Kruskal- } \\
\text { Wallis) }\end{array}$ & $<, 001$ & $<0,001$ \\
\hline
\end{tabular}

Os resultados mostraram diferença significativa entre os grupos para as bactérias gram-negativas ( $E$. coli $\mathrm{p}<0,001$ e $P$.aeruginosa $\mathrm{p}<0,001)$ havendo redução significante do número de UFC de E. coli (Grupos MI, EF, CT) e de $P$. aeruginosa (Grupo MI), quando comparado ao grupo controle. 
Discussão

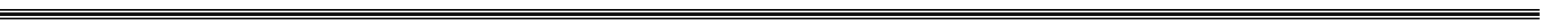




\section{DiscussÃo}

O biofilme acumulado na superfície interna de próteses totais pode funcionar como um reservatório para infecções locais e sistêmicas (Ramage et al., 2004; Verran, 2005), uma vez que é constituído por mais de 30 espécies diferentes entre bactérias e fungos (Nikawa et al., 1999). Tais microrganismos estão envolvidos no surgimento de patologias orais, como a Estomatite Protética (Ramage et al., 2004; Webb; Thomas; Whittle, 2005; Coco et al., 2008), bem como sistêmicas, como as endocardites (Li et al., 2000), pneumonias (Sumi et al., 2002), doenças pulmonares obstrutivas crônicas (Scannapieco, 2006), infecções generalizadas do sistema respiratório (Mojon et al., 1997) e outras desordens sistêmicas (Verran; Maryan, 1997; Nikawa; Hamada; Yamamoto, 1998; Senpuku et al., 2003; Coulthwaite; Verran, 2007).

A ação antimicrobiana dos produtos de higiene é uma variável importante a ser avaliada em decorrência da complexidade da composição e do grau de maturação do biofilme presente nas superfícies das próteses (Nikawa et al., 1999). A literatura reporta a importância da associação de um higienizador químico à escovação para a limpeza adequada de todas as regiões da prótese e obtenção de uma ação antimicrobiana eficaz (Nikawa et al., 1999; Shay, 2000; Kulak et al., 1997; Ramage et al., 2004).

O presente estudo teve como objetivo avaliar soluções higienizadoras de próteses à base de peróxidos alcalinos contra oito espécies microbianas relacionadas a doenças locais e sistêmicas, encontradas em biofilmes de próteses (Sumi et al., 2002, Barbeau et al., 2003; Coulthwaite et al., 2007, Coco et al., 2008, Glass et al., 2010; Kossion et al., 2011). Foi empregado o método isolado de imersão, isto é, sem a associação do método mecânico, buscando uma avaliação objetiva da ação antimicrobiana (Nikawa et al., 1999), uma vez que a associação com o método mecânico propicia um sinergismo de ação (Paranhos et al., 2009). Não foi empregado o biofilme misto, objetivando o conhecimento da ação antimicrobiana das soluções sobre cada microrganismo individualmente.

Os resultados mostraram que o peróxido alcalino Medical Interporous foi o mais efetivo, tendo ação sobre o biofilme de leveduras (C. albicans e C. glabrata), sobre três das quatro bactérias gram-positivas ( $S$. aureus, $S$. mutans e $E$. faecalis) e sobre ambas as bactérias gram-negativas ( $E$. coli e $P$. aeruginosa). Coenye et al. 
(2008) encontraram que o higienizador Medical Interporous, quando empregado conforme as orientações do fabricante e em 15 minutos de imersão, reduziu o número de $C$. albicans, S.aureus resistente à meticilina e P.aeruginosa. Jose et al. (2010) verificaram que a imersão por 15 minutos no peróxido Medical Interporous reduziu o biofilme in vitro de $C$. albicans, mas não o eliminou totalmente.

Segundo Glass et al. (2004), a efetividade do peróxido alcalino Medical Interpourous pode ser atribuída ao NitrAdine TM, um composto contido na formulação com propriedades de desinfecção, o qual apresenta alta atividade de remoção do biofilme in vitro contra uma variedade de microrganismos, tais como Candida albicans, Pseudomonas aeruginosa, Staphylococcus aureus, incluindo o tipo de MRSA, e vírus. Além disso, a presença de lauril sulfato de sódio (SLS), um detergente utilizado para solubilização de proteínas, pode também ser responsável pela ação de redução do biofilme. Moore et al. (1984) relataram que, em um grupo de seis higienizadores à base de peróxido, apenas dois apresentaram eficácia contra leveduras, o que poderia ser explicado pela presença de SLS na formulação desses higienizadores. Os resultados aqui encontrados, em relação às leveduras, são importantes, uma vez que esses microrganismos têm se mostrado resistentes à ação dos peróxidos. O higienizador Medical Interporous foi o único que apresentou ação contra C.albicans, o que confere vantagem de seu uso como higienizador de prótese total, especialmente em pacientes institucionalizados, dependentes e debilitados. A efetividade encontrada contra $C$. glabrata também é importante, uma vez que estudo prévio empregando metodologia semelhante mostrou ineficácia de um higienizador de peróxido alcalino (Bony Plus tablets -5 minutos) frente a esta cepa (Paranhos et al., 2009).

Os resultados em relação ao $S$. aureus também são importantes, uma vez que há controvérsias na literatura em relação à efetividade de peróxidos frente a esta cepa. Silva et al (2008) verificaram que higienizadores à base de perborato de sódio foram eficazes contra S.aureus. Lee et al.(2009) mostram que o uso de higienizador à base de peróxido alcalino (Steradent) em imersões de 5 minutos apresentou ação intermediária frente à Staphylococcus aureus resistentes à meticilina MRSA. Por outro lado, Paranhos et al. (2009) mostraram que a imersão em higienizador à base de peróxido alcalino (Bony Plus tablets), durante 5 minutos, não foi eficaz frente ao $S$. aureus. Tais divergências podem ser atribuídas às diferentes formulações dos higienizadores. 
Os resultados mostraram que o peróxido alcalino Efferdent Plus foi efetivo frente a cepas de $S$. mutans e E. coli; porém, apresentou ação intermediária sobre E. faecalis, $C$. glabrata e $P$. aeruginosa e moderada frente a $C$.albicans, $S$.aureus e B.sutilis. Nossos resultados concordam com Drake et al. (1992) que mostraram que o Efferdent (12 minutos) foi efetivo na redução da aderência de S.mutans e ineficaz contra cepas de C. albicans. Da mesma forma, Ferreira et al. (2009) e Vieira et al. (2010) também verificaram que o Efferdent não foi efetivo na remoção de C.albicans e C.glabrata. Gedik et al. (2009) mostraram que a imersão em Efferdent por 120 minutos foi eficaz na remoção de Candida, apesar de não prevenir sua adesão. Iseri et al. (2011) sugerem que a imersão noturna nesse higienizador possa aumentar o potencial antimicrobiano da solução, uma vez que períodos de 15, 30 e 60 minutos de imersão não foram suficientes para a descontaminação in vitro, não havendo eliminação de colônias de C.albicans. Coenye et al. (2008), ao avaliarem ação antimicrobiana de peróxidos alcalino frente a biofilmes de Candida albicans, Streptococcus mutans, Staphylococcus aureus resistentes à meticilina (MRSA) e $P$. aeruginosa verificaram que o Efferdent, assim como o Polident e Steradent apresentaram menor efetividade, principalmente sobre biofilmes de $C$. albicans formado em PMMA. Não há relatos na literatura sobre a ação antimicrobiana desse peróxido frente a cepas de B.sutilis, E. faecalis e E. coli.

A efetividade dos higienizadores Medical Interporous e Efferdent plus contra cepas de S. mutans concorda com estudos prévios, onde outros higienizadores de peróxidos alcalinos mostraram efetividade. Silva et al. (2008) verificaram que um higienizador a base de perborato de sódio a 3,8\% foi efetivo contra S.mutans. Li et al (2010) também mostraram que a imersão no peróxido alcalino Polident, durante 3 minutos foi eficaz na redução no número de S.mutans. Confirmando tais resultados, Lucena-Ferreira et al (2014) mostraram que a imersão diária no higienizador de peróxido alcalino Polident com enzima, durante 3 minutos, foi eficaz na redução total de microrganismos, incluindo o $S$. mutans, quando comparado ao grupo controle.

O E. faecalis é capaz de colonizar várias locais, incluindo a cavidade oral, e tem sido associado a lesões da mucosa bucal em pacientes imunodeprimidos. No presente estudo, o peróxido alcalino Medical Interporou foi efetivo contra essa cepa, enquanto o Efferdent plus apresentou ação intermediária. Tais resultados discordam dos achados de Paranhos et al., (2009), que verificaram que o método combinado 
foi mais efetivo que a imersão em peróxido alcalino (Bony Plus tablets - 5 minutos) na redução de $U F C / m L$ de $E$. faecalis.

Com relação à $P$. aeruginosa, este estudo mostrou que o higienizadores Medical Interporou foi eficaz enquanto os higienizadores Efferdent Plus e Corega Tabs apresentaram ação intermediária. Tais resultados confirmam os achados de Coenye et al. (2008), que verificaram que o higienizador Medical Interporous foi efetivo na redução de $P$. aeruginosa e discordam dos achados de Paranhos et al. (2009), onde a imersão no higienizador Bony Plus tablets por 5 minutos não apresentou efetividade. Não há na literatura outros relatos de estudos in vitro sobre a ação antimicrobiana de peróxidos alcalinos frente a esse microrganismo, que possam corroborar na comparação e discussão desses resultados.

A efetividade do peróxido alcalino Corega Tabs tem sido associada à presença de lauril sulfato de sódio associado ao perborato de sódio na formulação (Coenye et al., 2008; Dahmange et al., 2012), assim como de bicarbonato de sódio, uma vez que a presença de altas concentrações dessa substância leva a um efeito antimicrobiano, incluindo ação frente à C.albicans (Silhacek et al., 2005; Souza et al., 2009). Porém, os resultados mostraram que esse higienizador não apresentou ação frente a $S$. mutans, apresentando ação efetiva apenas contra B.subtillis e E.coli, e intermediária sobre a C.albicans, C. glabrata, S.aureus, E. faecalis, e $P$. aeruginosa. Souza et al (2009) e Gedick et al. (2009) mostraram que a imersão em Corega Tabs por 10 minutos, 120 minutos e período noturno, respectivamente, não foi eficaz na redução do número de colônias de $C$. albicans. Montagner et al. (2009) também verificaram que o higienizador Corega Tabs não foi eficaz frente a esta cepa quando empregado no tempo recomendado pelo fabricante (5 minutos). Entretanto, os achados de Fernandes et al. (2010) concluíram que esse higienizador, empregado em imersões de 5 minutos, foi efetivo no controle do biofilme de Candida spp, especialmente na redução de $C$. albicans, porém não foi capaz de eliminar totalmente as cepas, como o hipoclorito de sódio a 0,5\%.

Da mesma forma, não há na literatura relatos de estudos in vitro abordando a ação antimicrobiana do Corega Tabs frente a cepas de S.aureus, S. mutans, $B$. subtilis, E. faecalis, P. aeruginosa e E.coli. Neste estudo, o peróxido Corega tabs apresentou ação efetiva contra o B.subtillis e E. coli. Nossos resultados diferem de Silva et al. (2008), onde foi verificado ineficácia de higienizadores sobre espécimes de 
resina acrílica contaminados com $B$. subtilis, porém foram empregadas pastilhas efervescentes contendo apenas perborato de sódio.

O presente estudo verificou que todos os higienizadores à base de peróxido alcalino foram efetivos contra E.coli. Entretanto, a literatura relata apenas dois estudos frente tal microrganismo, sendo que ambos mostraram ineficácia dos peróxidos alcalinos (Silva et al., 2008; Paranhos et al., 2009). As divergências podem ser atribuídas aos diferentes higienizadores empregados, ou seja, perborato de sódio e Bony Plus tablets.

Uma limitação da pesquisa foi a avaliação dos microrganismos individualmente, sendo importante que estudos futuros envolvam biofilmes mistos para a obtenção de dados relacionados à interação microbiana.

A manutenção dos aparelhos protéticos em bom estado de higiene continua sendo um desafio tanto para os pacientes, como para os profissionais cirurgiõesdentistas. Em relação aos higienizadores, um requisito importante refere-se a sua efetividade frente ao controle do biofilme. Os diferentes resultados obtidos no presente estudo em relação aos higienizadores sobre as diferentes cepas podem indicar o potencial patogênico de cada espécie e as diferenças entre as formulações de cada higienizador à base de peróxidos alcalinos. 


\section{Conclusão}




\section{ConcLusÃo}

Com base nas condições experimentais do presente estudo e de acordo com a metodologia empregada, foi possível concluir que o higienizador Medical Interporous foi o mais eficaz, apresentando ação antimicrobiana sobre os biofilmes de C. albicans, C. glabrata, S. aureus, S. mutans, E. faecalis, E. coli e $P$. aeruginosa. 


\section{Referências"}

* De acordo com: International Committee of Medial Journal Editors, adaptado pela U.S. National Library of Medicine (estilo Vancouver). Disponível em: http://www.ncbi.nlm.nih.gov/bookshelf/br. fcgi?book=citmed 


\section{REFERÊNCIAS}

1. Abelson DC. Denture plaque and denture cleansers. J Prosthet Dent. $1981 ; 45(4): 376-9$.

2. Abelson DC. Denture plaque and denture cleansers: review of the literature. Gerodontics. 1985;1(5):202-6.

3. Abere DJ. Post-placement care of complete and removable partial dentures. Dent Clin North Am. 1979;23(1):143-51.

4. Andrade IM, Cruz PC, Silva $\mathrm{CH}$, Souza RF, Paranhos HF, Candido RC, Marin JM, Souza-Gugelmin MC. Effervescent tablets and ultrasonic devices agaist Candida and mutans streptococci in denture biofilm. Gerodontology. $2011 ; 28(4): 264-70$

5. Andre RFG, Andrade IM, Silva-Lovato $\mathrm{CH}$, Paranhos HFO, Pimenta FC, Ito IY. Prevalence of mutans streptococci isolated from complete dentures and their susceptibility to mouthrinses. Braz Dent J. 2011;22(1):62-67.

6. Akar GC, Ergul S. The oral hygiene and denture status among residential home residents. Clin Oral Investig 2008;12(1):61-5.

7. Arendorf TM, Walker DM. Denture stomatitis: a review. J Oral Rehabil. 1987;14(3):217-27.

8. Augsburger $\mathrm{RH}$, Elahi JM. Evaluation of seven proprietary denture cleansers. J Prosthet Dent. 1982;47(4):356-9

9. Azevedo NF, Cerca N. Biofilmes - Na Saúde, no Ambiente, na Indústria. $1^{\circ}$ ed., Publindústria Ed. 2012.

10. Barbeau J, Seguin J, Goulet JP, Koninck L, Avon SL, Lalonde B, Rompré P, Deslauriers N. Reassessing the presence of Candida albicans in denture related stomatitis. Oral Surg Oral Med Oral Pathol Oral Radiol Endod. 2003;95(1):51-9.

11. Budtz-Jørgensen E, Kelstrup J. Enzyme as denture cleansers. Scand. J. Dent. Res. 1977;85(3):209-15. 
12. Budtz-Jørgensen E. Prevention of denture plaque formation by an enzyme denture cleanser. J Biol Buccale. 1977;5(3):239-44.

13. Budtz-Jørgensen E. A 3-months' study of enzymes as denture cleansers. J Oral Rehabil. 1978;5(1):35-9.

14. Budtz-Jørgensen E. Materials and methods for cleaning dentures. J Prosthet Dent. 1979;42(6):619-23.

15. Campos M S, Marchini L, Bernardes LS, Paulino LC, Nobrega FG. Biofilm microbial communities of denture stomatitis. Oral microbiology and immunology. 2008;23(5),419-24.

16. Catão CDS, Ramos INC, Silva Neto JM, Duarte SMO, Batista AUD, Dias AHM. Chemical substance efficiency in the biofilm removing in complete denture. Rev Odontol Unesp. 2007;36(1):53-60.

17. Coco BJ, Bagg J, Cross LJ, Jose A, Cross J, Ramage G. Mixed Candida albicans and Candida glabrata populations associated with the pathogenesis of denture stomatitis. Oral Microbiol Immunol. 2008; 23(5):377-83.

18. Coelho CM, Souza YT, Daré AM. Denture-related oral mucosal lesions in a Brazilian school of dentistry. J Oral Rehabil. 2004;31(2):135-9.

19. Coenye T, De Prijck K, De Wever B, Nelis HJ. Use of the modified Robbins device to study the in vitro biofilm removal efficacy of NitrAdine, a novel disinfecting formula for the maintenance of oral medical devices. J Appl Microbiol. 2008;105(3):733-40.

20. Cole EC, Robison R. Test methedology for evaluation of germicides. In: Ascenzi JM, ed. Handbook of Disinfectants and Antiseptics. New York: Marcel Dekker; 1996:1-13.

21. Coulthwaite L, Verran J. Potential pathogenic aspects of denture plaque. $\mathrm{Br}$ Dent J. 2007;64(4):180-9.

22. Council on Dental Materials, Instruments and Equipment. Denture cleansers. J Am Dent Assoc. 1983;106(1):77-9.

23. Cruz PC, Andrade IM, Peracini A, Souza-Gugelmin MC, Silva-Lovato $\mathrm{CH}$, Souza RF, Paranhos HF. The effectiveness of chemical denture cleansers and 
ultrasonic device in biofilm removal from complete dentures. J Appl Oral Sci. 2011;19(6):668-73.

24. Cumming CG, Wight C, Blackwell CL, Wray D. Denture stomatitis in the elderly. Oral Microbiol Immunol. 1990;5(2):82-5.

25. Davey AL, Rogers AH. Multiple types of the Streptococcus mutans in the human mouth and their intra-family transmission. Arch Oral Biol. 1984;29(6):453-60.

26. De Paola LG, Minah GE, Elias AS. Evaluation of agentes to reduce microbial growth on dental prostheses of myelosupressed cancer patients. Clinic Prevent Dent. 1984;6(2):9-12.

27. Dhamande MM, Pakhan AJ, Thombare RU, Ghodpage SL. Evaluation of efficacy of commercial denture cleansing agents to reduce the fungal biofilm activity from heat polymerized denture acrylic resin: an in vitro study. Contemp Clin Dent. 2012;3(2):168-72.

28. Dikbas I, Koksal T, Calikkocaoglu S. Investigation of the cleanliness of dentures in a university hospital. Int J Prosthodont. 2006;19(3), 294-8.

29. Dills SS, Olshan AM, Goldner S, Brogdon C. Comparison of the antimicrobial capability of an abrasive paste and chemical-soak denture cleaners. J Prosthet Dent. 1988;60(4):467-70.

30. Drake $D$, Wells J, Ettinger R. Efficacy of denture cleansing agents in an in vitro bacteria-yeast colonization model. Int J Prosthodont. 1992; 5(3): 214-20.

31. Duyck J, Vandamme K, Muller P, Teughels W. Overnight storage of removable dentures in alkaline peroxide-based tablets affects biofilm mass and composition. J Dent. 2013;41(12),1281-9.

32. El-Solh AA. Association between pneumonia and oral care in nursing home residents. Lung. 2011;189(3):173-80.

33. Felton D, Cooper L, Duqum I, Minsley G, Guckes A, Haug S, Meredith P, Solie C, Avery D, Deal Chandler N. Evidence-based guidelines for the care and maintenance of complete dentures: a publication of the American College of Prosthodontists. J Prosthodont. 2011;20(1),S1-S12. 
34. Fernandes FDS, Pereira-Cenci T, da Silva WJ, Filho AP, Straioto FG, Del Bel Cury AA. Efficacy of denture cleansers on Candida spp. biofilm formed on polyamide and polymethyl methacrylate resins. J Prosthet Dent. 2011;105(1):51-8.

35. Ferreira MA, Pereira-Cenci T, Rodrigues de Vasconcelos LM, RodriguesGarcia RC, Del Bel Cury AA. Efficacy of denture cleansers on denture liners contaminated with Candida species. Clinical oral investigations 2009;13(2), 237-42.

36. Gedik H, Öskan YK. The effect of surface roughness of silicone-based resilient liner materials on the adherence of Candida albicans and inhibition of Candida albicans with different disinfectants. Oral Health Prev Dent. 2009;7(4):347-53.

37. Ghalichebaf M, Graser GN, Zander HA. The efficacy of denture-cleansing agents. J Prosthet Dent. 1982;48(5):515-20.

38. Glass RT, Bullard JW, Conrad RS, Blewett EL. Evaluation of the sanitization effectiveness of a denture-cleaning product on dentures contaminated with known microbial flora. An in vitro study.Quintess. Int. 2004;35(3):194-9.

39. Glass RT, Conrad RS, Bullard JW,Goodson LB, Mehta A, Stanley JL et al. Evaluation of microbial flora found in previously worn prostheses from the northeast and southwest regions of the United States. J Prosthet Dent. 2010; 103(6):384-9.

40. Glass RT, Conrad RS, Bullard JW,Goodson LB, Mehta A, Lech SJ et al. Evaluation of cleansing methods for previously worn prostheses.Compend Contin Educ Dent. 2011;32(3):68-73.

41. Gornitsky M, ParadisI I, Landaverde G, Malo AM, Velly AM. A clinical and microbiological evaluation of denture cleansers for geriatric patients in longterm care institutions. J Can Dent Assoc. 2002;68(1):39-45.

42. Haumschild MS, Haumschild RJ. The importance of oral health in long-term care. J Am Med Dir Assoc. 2009;10(9):667-71.

43. Henderson CW, Schwartz RS, Herbold ET, Mayhew RB. Evaluation of the barrier system, an infection control system for the dental laboratory. J Prosthet Dent. 1987;58(4):517-21. 
44. Işeri U, Uludamar A, Ozkan Y K. Effectiveness of different cleaning agents on the adherence of Candida albicans to acrylic denture base resin. Gerodontology. 2011;28(4), 271-6 (2011).

45. Jagger DC, Harrison A. Denture cleansing-the best approach. $\mathrm{Br}$ Dent $\mathrm{J}$. 1995;178(11):413-7.

46. Jose A, Coco B, Milligan S, Young B, Lappin DF, Bagg J, Murray C, Ramage G. Reducing the incidence of denture stomatitis: are denture cleansers sufficient? J Prosthodont. 2010:19(4):252-7.

47. Lee D, Howlett J, Pratten J, Mordan N, McDonald A, Wilson M, Ready D. Susceptibility of MRSA biofilms to denture-cleansing agents. FEMS Microbiology Lett. 2009;291(2),241-6.

48. Lee, H.-E., Li, C.-Y., Chang, H.-W., Yang, Y.-H. \& Wu, J.-H. Effects of different denture cleaning methods to remove Candida albicans from acrylic resin denture based material. J. Dental Scien. 2011;6: 216-220.

49. Li X, Kolltveit KM, Tronstad L, Olsen I. Systemic diseases caused by oral infection. Clin Microbial Rev. 2000;13(4):547-58.

50. Li L, Finnegan MB, Özkan S, Kim Y, Lillehoj PB, Ho CM, Lux R, Mito R, Loewy $Z$, Shi W. In vitro study of biofilm formation and effectiveness of antimicrobial treatment on various dental material surfaces. Mol Oral Microbiol. 2010;25(6),384-90.

51. Lucena-Ferreira SC, Ricomini-Filho AP, Da Silva WJ, Cury JA, Del Bel Cury AA. Influence of daily immersion in denture cleanser on multispecies biofilm. Clinical Oral Investigations. 2014;doi:10.1007/s00784-014-1210-9.

52. Keng SB, Lim M. Denture plaque distribution and the effectiveness of a perborate- containing denture cleanser. Quintessence Int. 1996;27(5):341-5.

53. Kulak Y, Arikan A, Albak S, Okar I, Kazazoğlu E. Scanning electron microscopic examination of different cleaners: surface contaminant removal from dentures. J Oral Rehabil. 1997;24(3):209-15.

54. Kulak-Ozkan Y, Kazazoglu E, Arikan A. Oral hygiene habits, denture cleanliness, presence of yeasts and stomatitis in elderly people. J Oral Rehabil. 2002;29(3),300-4. 
55. Kossioni AE. The prevalence of denture stomatitis and its predisposing conditions in an older Greek population. Gerodontology. 2011;28(2):85-90.

56. Kumar MN, Thippeswamy HM, Raghavendra Swamy KN, Gujjari AK. Efficacy of commercial and household denture cleansers against Candida albicans adherent to acrylic denture base resin: an in vitro study. Indian $\mathrm{J}$ Dent Res. 2012;23(1):39-42.

57. MacCallum M, Stafford GD, MacCulloch WT, Combe EC. Wich cleanser? A report on a survey of denture cleansing routine and the development of a new denture cleanser. Dent Pract Dent Rec. 1968;19(3):83-9.

58. Marra J, Paleari AG, Rodriguez LS, Leite ARP, Pero AC, Compagnoni MA. Effect of an acrylic resin combined with an antimicrobial polymer on biofilm formation. J Appl Oral Sci. 2012;20(6):643-8.

59. Marchini L, Tamashiro E, Nascimento DF, Cunha VP. Self-reported denture hygiene of a sample of edentulous attendees at a University dental clinic and therelationship to the condition of the oral tissues. Gerodontology. 2004; 21(4):226-228.

60. Montagner $\mathrm{H}$, Montagner F, Braun KO, Peres PE, Gomes BP. In vitro antifungal action of different substances over microwaved-cured acrylic resins. J Appl Oral Sci. 2009;17(5),432-5.

61. Moore TC, Smith DE, Kenny GE. Sanitization of dentures by several denture hygiene methods. J Prosthet Dent. 1984; 52(2),158-63.

62. Mojon P, Budtz-Jørgensen E, Michel JP, Limeback H. Oral health and history of respiratory tract infection in frail institutionalised elders. Gerodontol. 1997;14(1):9-16.

63. Nakamoto K, Tamamoto M, Hamada T. Evaluation of denture cleansers with and without enzymes against Candida albicans. $J$ Prosthet Dent. $1991 ; 66(6): 792-5$

64. Neill DJ. A study of materials and methods employed in cleaning dentures. $\mathrm{Br}$ Dent J. 1968;124(3):107-15.

65. Neppelenbroek KH, Pavarina AC, Spolidorio DM, Vergani CE, Mima EG, Machado AL. Effectiveness of microwave sterilization on three hard chairside reline resins. Int J Prosthodont. 2003;16(6):616-20. 
66. Neppelenbroek KH. Efetividade de desinfecção de próteses totais por energia de microondas no tratamento da estomatite protética associada à Candida spp. [tese]. Araraquara: Universidade Estadual Paulista, Faculdade de Odontologia; 2005.

67. Nikawa H, Yamamoto T, Hamada T, Sadamori S, Agrawal S. Cleansing efficacy of commercial denture cleansers: ability to reduce Candida albicans biofilm activity. Int J Prosthodont. 1995;8(6):527-534.

68. Nikawa H, Hamada $\mathrm{T}$, Yamamoto $\mathrm{T}$. Denture plaque - past and recent concerns. J Dent. 1998;26(4):299-304.

69. Nikawa $\mathrm{H}$, Hamada $\mathrm{T}$, Yamashiro $\mathrm{H}$, Kumagai $\mathrm{H}$. A review of in vitro and in vivo methods to evaluate the efficacy of denture cleansers. Int $\mathrm{J}$ Prosthodont. 1999;12(2):153-9

70. Pace CC, McCullough GH. The association between oral microorgansims and aspiration pneumonia in the institutionalized elderly: review and recommendations. Dysphagia. 2010;25(4):307-22.

71. Panariello BHD. Eficácia da imersão e da escovação mecânica combinada com diferentes agentes de limpeza de próteses na redução da viabilidade de biofilme multiespécies [tese]. Araraquara: Faculdade de Odontologia de Araraquara, Universidade Estadual Paulista Júlio de Mesquita Filho; 2013

72. Paranhos HFO, Silva-Lovato $\mathrm{CH}$, Souza RF, Cruz PC, Freitas KM, Peracini A. Effects of mechanical and chemical methods on denture biofilm accumulation. $J$ Oral Rehabil. 2007a;34(8):606-12.

73. Paranhos HFO, Silva-Lovato CH, Venezian GC, Macedo LD, Souza RF. Distribution of biofilm on internal and external surfaces of upper complete dentures: the effect of hygiene instruction. Gerodontology. 2007b;24(3):162-8.

74. Paranhos HFO, Davi LR, Peracini A, Soares RB, Silva-Lovato CH, Souza RF. Comparison of physical and mechanical properties of microwave-polymerized acrylic resin after disinfection in sodium hypochlorite solutions. Braz Dent J. 2009;20(4):331-335.

75. Pavarina AC, Pizzolitto AC, Machado AL, Vergani CE, Giampaolo ET. An infection control protocol: effectiveness of immersion solutions to reduce the microbial growth on dental prostheses. J Oral Rehabil. 2003;30(5):532-6. 
76. Pellizzaro D, Polyzois G, Machado AL, Giampaolo ET, Sanitá PV, Vergani CE. Effectiveness of mechanical brushing with different denture cleansing agents in reducing in vitro Candida albicans biofilm viability. Braz Dent $\mathrm{J}$. 2012;23(5),547-54.

77. Peracini A. Soluções higienizadoras de prótese total: avaliação da remoção de biofilme e efeito sobre propriedades da resina acrílica termopolimerizável [tese]. Ribeirão Preto: Faculdade de Odontologia de Ribeirão Preto,Universidade de São Paulo; 2012.

78. Pereira-Cenci T, Da Silva WJ, Cenci MS, Cury AA. Temporal changes of denture plaque microbiologic composition evaluated in situ. Int $\mathrm{J}$ Prosthodont. 2010;23(3):239-42.

79. Pereira-Cenci T, Da Silva WJ, Cenci MS, Cury AA. Temporal changes of denture plaque microbiologic composition evaluated in situ. Int $\mathrm{J}$ Prosthodont. 2010;23(3):239-42.

80. Powell GL, Runnells RD, Saxon BA, Whisenant BK. The presence and identification of organisms transmitted to dental laboratories. J Prosthet Dent. $1990 ; 64(2), 235-7$.

81. Raab FJ, Taylor CA, Bucher JA, Mann BL. Scanning electron microscopic examination of ultrasonic and effervescent methods of surface contaminant removal from complete dentures. J Prosthet Dent. 1991;65(2):255-8.

82. Ramage G, Tomsett K, Wickes BL, López-Ribot JL, Redding SW. Denture stomatitis: A role for Candida biofilms. Oral Sur Oral Med Oral Pathol Oral Radiol Endod. 2004;98(1):53-9.

83. Ramage G, Zalewska A, Cameron DA, Sherry L, Murray C, Finnegan MB, Loewy ZG, Jagger DC. A comparative in vitro study of two denture cleaning techniques as an effective strategy for inhibiting Candida albicans biofilms on denture surfaces and reducing inflammation. J Prosthodont. 2012;21(7),516-22.

84. Roessler DM. Complete denture success for patients and dentists. Int Dent J. 2003;53(5 Suppl):340-5.

85. Rossato MB, Unfer B, May LG, Braun KO. Analysis of the effectiveness of different hygiene procedures used in dental prostheses. Oral Health Prev Dent. 2011;9(3):221-7. 
86. Rudd RW, Senia ES, McCleskey FK, Adams ED Jr. Sterilization of complete dentures with sodium hypochlorite. J Prosthet Dent. 1984 Mar;51(3):318-21.

87. Rustogi KN, Mellberg JR, Schlissel HJ, Hansen KR, Volpe AR. The clinical efficacy of denture cleansers. Q Natl Dent Assoc. 1979 Apr;37(3):100-6.

88. Senpuku H, Sogame A, Inoshita E, Tsuha Y, Miyazaki H, Hanada N. Systemic diseases in association with microbial species in oral biofilm from elderly requiring care. Gerontology. 2003;49(5):301-9.

89. Shay K. Denture hygiene: a review and update. J Contemp Dent Pract. 2000;1(2):28-41

90. Sheen SR, Harrison A. Assessment of plaque prevention on dentures using an experimental cleanser. J Prosthet Dent. 2000;84(6):594-601.

91. Silva FC, Kimpara ET, Mancini MN, Balducci I, Jorge AO, Koga-Ito CY. Effectiveness of six different disinfectants on removing five microbial species and effects on the topographic characteristics of acrylic resin. J Prosthodont. 2008;17: 627-33.

92. Silva-Lovato $\mathrm{CH}$, Paranhos HFO, Mello PC, Cruz PC, Freitas KM, Macedo LD. Levantamento do grau de instruções e dos materiais e métodos de higiene utilizados por usuários de próteses totais. Rev Odontol Unesp. 2006;35(2):12531.

93. Silva-Lovato $\mathrm{CH}$, Wever Bd, Adriaens E, Paranhos Hde F, Watanabe E, Pisani MX, Souza RF, Ito IY. Clinical and antimicrobial efficacy of NitrAdine ${ }^{\text {TM}}$-based disinfecting cleaning tablets in complete denture wearers. $J$ Appl Oral Sci. 2010;18(6):560-5.

94. Sousa FAGC, De Paradella TC, Koga-Ito CY, Jorge AO. Effect of sodium bicarbonate on Candida albicans adherence to thermally activated acrylic resin. Braz Oral Res. 2009;23(4),381-5.

95. Srinivasan M, Gulabani M. A microbiological evaluation of the use of denture cleansers in combination with an oral rinse in complete denture patients. Indian J Dent Res. 2010 Jul-Sep;21(3):353-6.

96. Sumi Y, Miura H, Sunakawa M, Michiwaki Y, Sakagami N. Colonization of denture plaque by respiratory pathogens in dependent elderly. Gerodontology. 2002;19(1):25-9. 
97. Tarbet WJ, Axelrod S, Minkoff S, Fratarcangelo PA. Denture cleansing: a comparison of two methods. J Prosthet Dent. 1984;51(3):322-5.

98. Telles D. Prótese Total - Convencional e Sobre Implantes. $1^{\text {a }}$ ed., Santos Livraria e Ed., 2009.

99. Uludamar A, Ozkan YK, Kadir T, Ceyhan I. In vivo efficacy of alkaline peroxide tablets and mouthwashes on Candida albicans in patients with denture stomatitis. J Appl Oral Sci. 2010 May-Jun;18(3):291-6.

100. Verran J, Maryan CJ. Retention of Candida albicans on acrylic resin and silicone of different surface topography. J Prosthet Dent. 1997 May;77(5):535-9.

101. Verran J. Malodour in denture wearers: an ill-defined problem. Oral Dis. 2005;11 supp. $1: 24-8$

102. Vieira APC, Senna PM, Silva WJ, Da Del Bel Cury AA. Long-term efficacy of denture cleansers in preventing Candida spp. biofilm recolonization on liner surface. Braz Oral Res. 2010;24(3),342-8.

103. Webb BC, Thomas CJ, Whittle T. A 2-year of Candida-associated denture stomatitis treatment in aged care subjects. Gerodontology. 2005;22(3):168-76.

104. Zarb GA, Hobkirk JA, Eckert ES, Jacob RF. Tratamentos Protéticos para pacientes edêntulos - Próteses Totais Convencionais e Implantossuportada. 13ํㅡ. Ed., Elsevier Ed. 2013

105. Zissis AJ, Polyzois GL, Yannikakis SA, Harrison A. Roughness of denture materials: a comparative study. Int J Prosthodont. 2000; 13(2): 136-40. 